ORNL/TM-13132

\title{
Tritium Monitoring Techniques
}

\author{
RECEIVES \\ Mal 23 T \\ J. R. DeVore \\ M. A. Buckner \\ OSTI
}

WAMAGED AND OPERATED EY

LOCKHEED WARNW EMERGY RESEARCH CORPORATION

FOR THEUNTED STATES

DEPARTUECT OF BERGY 
This report has been reproduced directly from the best available copy.

Available to DOE and DOE contractors from the Otfice of Scientific and Technical Information, P.O. Box 62, Oak Ridge, TN 37831; prices available from (615) 576-8401, FTS 626-8401.

Available to the public from the National Technical Information Service, U.S. Department of Commerce, 5285 Port Royal Rd., Springfield, VA 22161.

This report was prepared as an account of work sponsored by an agency of the United States Government. Neither the United States Government nor any agency thereof, nor any of their employees, makes any warranty, express or implied, or assumes any legal liability or responsibility for the accuracy, completeness, or usefulness of any information, apparatus, product, or process disclosed, or represents that its use would not infringe privately owned rights. Reference herein to any specific commercial product, process, or service by trade name, trademark, manufacturer, or otherwise, does not necessarily constitute or imply its endorsement, recommendation, or favoring by the United States Government or any agency thereof. The views and opinions of authors expressed herein do not necessarily state or reflect those of the United States Government or any agency thereof. 


\section{DISCLAIMIER}

Portions of this document may be illegible in electronic image products. Images are produced from the best available original document. 


$$
\text { ORNL/TM- } 13132
$$

Instrumentation and Controls Division

\title{
TRITIUM MONITORING TECHNIQUES
}

\author{
J. R. DeVore \\ M. A. Buckner
}

Date Published-May 1996

Prepared by

OAK RIDGE NATIONAL LABORATORY

Oak Ridge, Tennessee 37831-6285

managed by

LOCKHEED MARTIN ENERGY RESEARCH CORP.

for the

U.S. DEPARTMENT OF ENERGY

under contract DE-AC05-96OR22464 
. 


\section{CONTENTS}

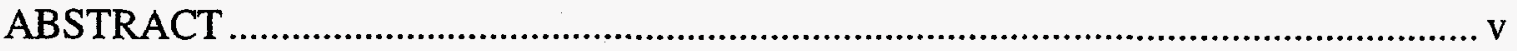

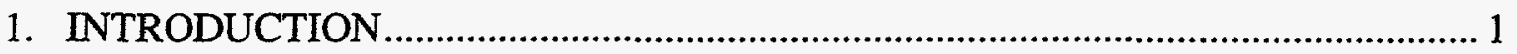

2. TRITIUM MONITOR PERFORMANCE SPECIFICATIONS ............................... 1

3. DESIGN APPROACHES TO TRITIUM DETECTION AND MONITORING .......... 1

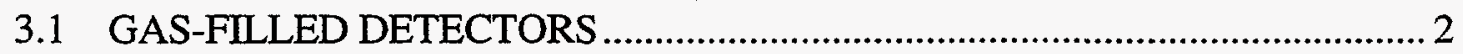

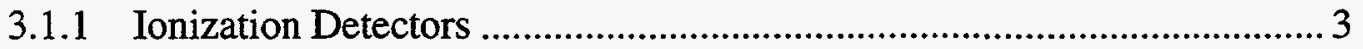

3.1.2 Proportional Detectors.................................................................... 4

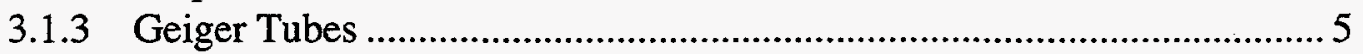

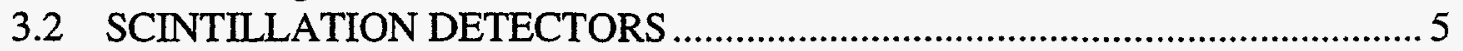

3.2.1 Liquid Scintillation Detectors ........................................................ 5

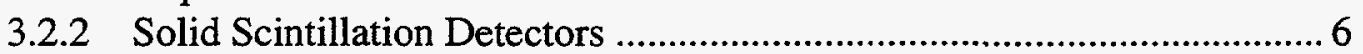

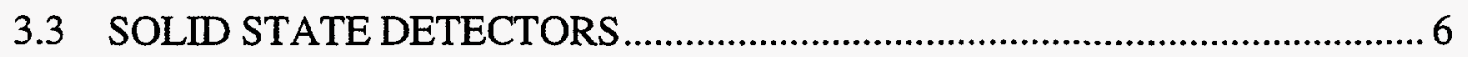

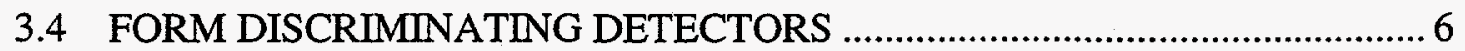

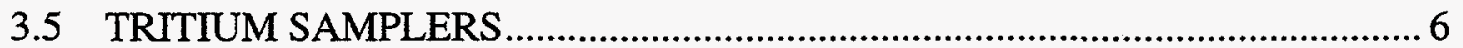

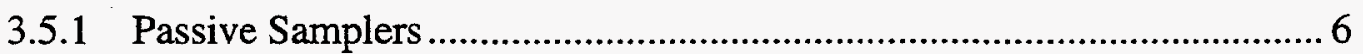

3.5.2 Active Samplers .......................................................................... 7

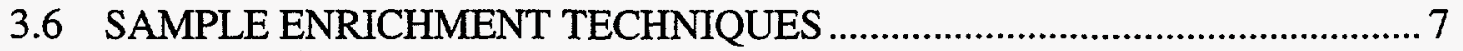

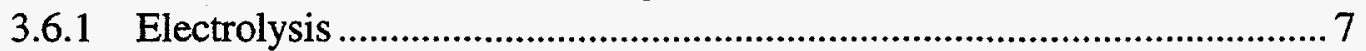

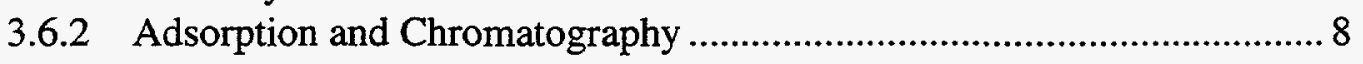

4. TRITIUM MONITORS DEVELOPED FOR SPECIFIC APPLICATIONS ............... 8

4.1 GAS FLOW PROPORTIONAL COUNTER ……......................................... 8

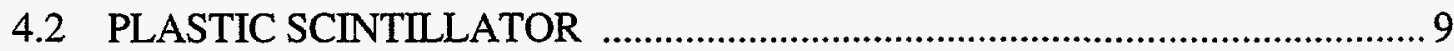

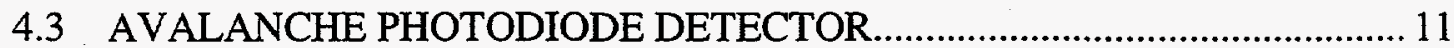

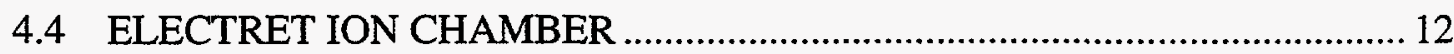

5. EXISTING COMMERCIALLY AVAILABLE TRITIUM MONITORING

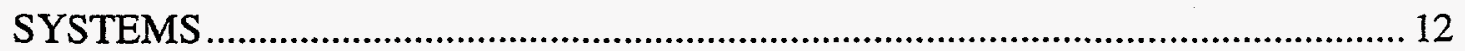

5.1 BECTON DICKINSON DIAGNOSTIC INSTRUMENT SYSTEMS ...............13

5.1.1 Response to Proposal Request........................................................... 14

5.2 EG\&G NUCLEAR INSTRUMENTS DIVISION ...................................... 14

5.2.1 Response to Proposal Request....................................................... 16

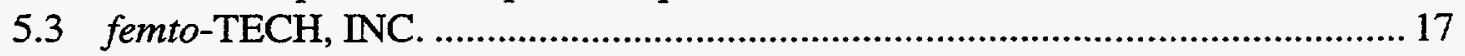

5.3.1 Response to Proposal Request...................................................... 19 


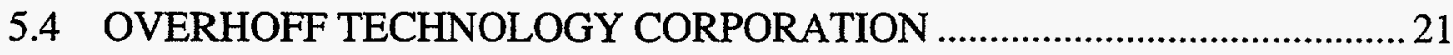

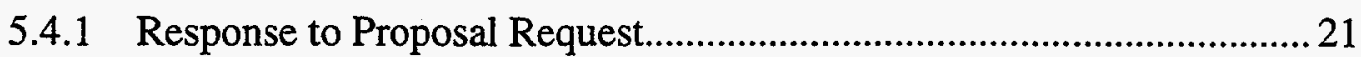

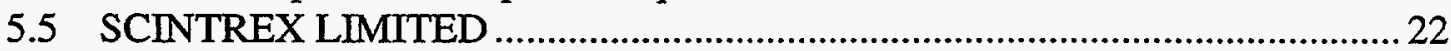

5.5.1 Response to Proposal Request............................................................. 23

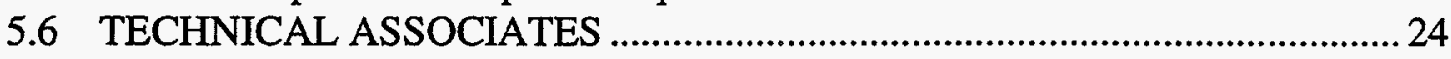

5.6.1 Response to Proposal Request................................................................ 25

6. COST, SCHEDULE, AND PERFORMANCE TRADE-OFFS ….............................26

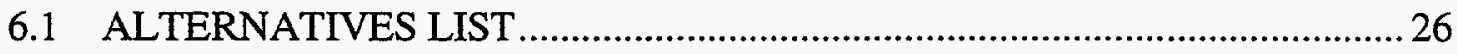

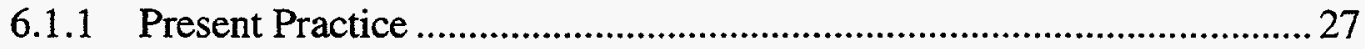

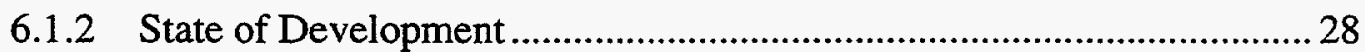

6.1.3 Low-Level Tritium Dosimetry ............................................................ 28

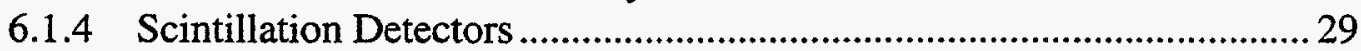

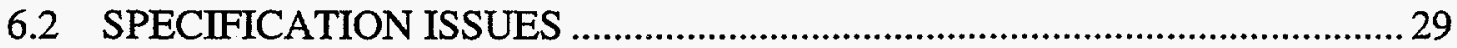

6.2.1 Neutron Background .......................................................................... 29

6.2.2 Sensitivity, Accuracy, Detector Size, and Response Time......................29

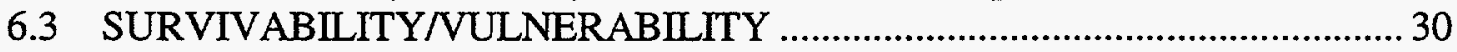

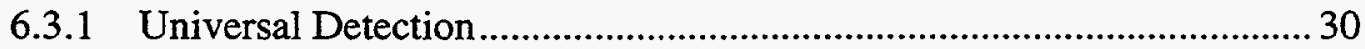

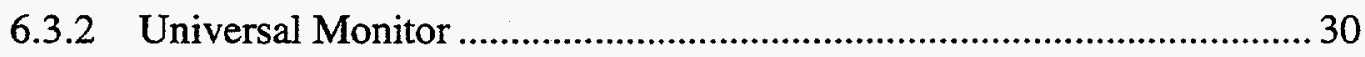

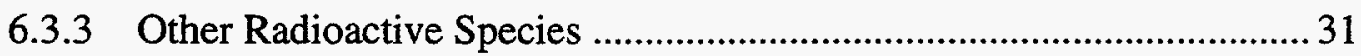

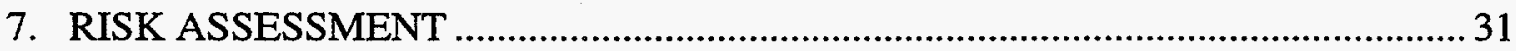

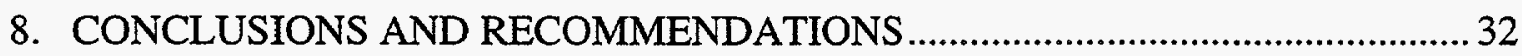

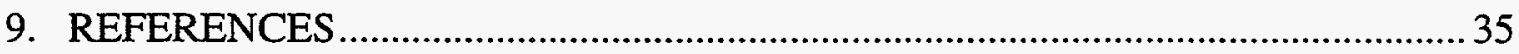

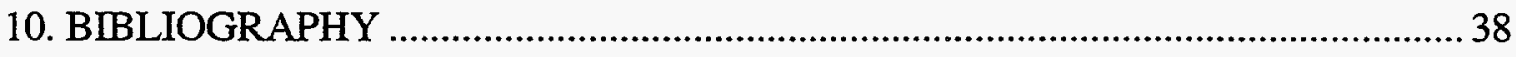

APPENDIX A: COMPANIES WITH COMMERCIAL TRITIUM MONITORING

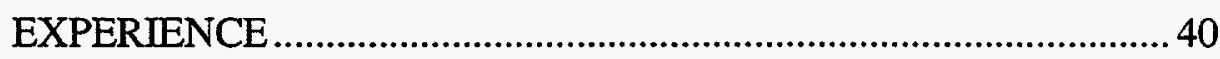

APPENDIX B: SPECIFICATION FOR TRITIUM MONITOR SENT FOR PROPOSAL REQUEST.

APPENDIX C: femto-TECH QUESTIONS AND SUGGESTIONS FOR TRITIUM MONITOR. 


\begin{abstract}
As part of their operations, the U.S. Navy is required to store or maintain operational nuclear weapons on ships and at shore facilities. Since these weapons contain tritium, there are safety implications relevant to the exposure of personnel to tritium. This is particularly important for shipboard operations since these types of environments can make low-level tritium detection difficult. Some of these ships have closed systems, which can result in exposure to tritium at levels that are below normally acceptable levels but could still cause radiation doses that are higher than necessary or could hamper ship operations. This report describes the state of the art in commercial tritium detection and monitoring and recommends approaches for low-level tritium monitoring in these environments.
\end{abstract}




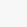




\section{INTRODUCTION}

As part of their operations, the U.S. Navy is required to store or maintain operational nuclear weapons on certain ships and at some shore facilities. Since these weapons contain tritium, there are safety implications relevant to the exposure of personnel to tritium, which has the potential for leakage from these devices. This is particularly important for shipboard operations since these types of environments can make low-level tritium detection difficult. Some of these ships have closed systems, which can result in continuous (168-h/week) exposure to tritium at levels that, although they are below the normally acceptable levels, could cause radiation doses that are higher than necessary or result in unnecessary emergency measures because of suspected leakage that could hamper ship operations.

The purpose of this report is to survey existing tritium monitoring technology in order to determine if there are recent advances in the field which are usable for this monitoring application.

\section{TRITIUM MONITOR PERFORMANCE SPECIFICATIONS}

The shipboard tritium monitor requirements include providing continuous monitoring at or below maximum permissible concentrations and providing universal detection of tritium in both dusts and gases, thus eliminating the requirement for two types of monitors aboard ships. The monitor is also required to use techniques for detection and signal processing which permit the greatest possible sensitivity, noise immunity from electromagnetic interference (EMI), operation without false alarms in a shipboard environment, and low sensitivity to radiation background. The detector cannot be made larger than present detectors because of size and weight limitations. The relevant performance specifications are shown in Table 1. Other relevant specifications are provided in Table 2.

\section{DESIGN APPROACHES TO TRITIUM DETECTION AND MONITORING}

Tritium detection has been accomplished with a high degree of success despite the difficulties encountered with the very low energy radiation that it produces. The following is a discussion of techniques for measuring low-level tritium concentrations. It is not intended to be an exhaustive list of all possible variations of tritium monitoring techniques. For a more complete discussion, the reader is referred to Refs. 1-3. Emphasis will be given in later sections to those techniques thought applicable to the problem at hand. 
Table 1. Navy tritium monitor performance specifications

Item Specification

Sensitivity

Accuracy

Alarm

Operating range

Operating background

Calibration

Response time

Survivability/vulnerability
Detect minimum of 0.1 to $1.0 \mu \mathrm{Ci}$ tritium $/ \mathrm{m}^{3}$ of gas in a $0.1-\mathrm{mR} / \mathrm{h}{ }^{60} \mathrm{Co}$ background and a $0.1-\mathrm{rem} / \mathrm{h}$ multienergy neutron background.

Measure 0.1 to $1.0 \mu \mathrm{Ci}$ tritium $/ \mathrm{m}^{3}$ of gas in a $0.1-\mathrm{mR} / \mathrm{h}$ ${ }^{60} \mathrm{Co}$ background and a $0.1-\mathrm{rem} / \mathrm{h}$ multienergy neutron background with a $\pm 20 \%$ accuracy at the $95 \%$ confidence level.

Audible and visual, capable of being set anywhere on the operating range.

0.1 to 1.0 , to $10,000 \mu \mathrm{Ci}$ tritium $/ \mathrm{m}^{3}$ of gas .

Operate without false alarm with the alarm set at $2 \mu \mathrm{Ci} / \mathrm{m}^{3}$ or greater in a $1-\mathrm{mR} / \mathrm{h}{ }^{60} \mathrm{Co}$ background and a $0.1-\mathrm{rem} / \mathrm{h}$ multienergy neutron background.

In a shipboard environment, hold calibration at any point on the operating range with an accuracy of $\pm 20 \%$ for a period of 2 years.

Respond to a $75 \%$ step input of $0.2 \mu \mathrm{Ci} / \mathrm{m}^{3}$ within $2 \mathrm{~min}$.

MIL-S-901 Class I grade A shock test and MLL-E-16400 type I vibration test including temperature and humidity for range 4 requirements.

\subsection{GAS-FILLED DETECTORS}

Gas-filled detectors function by the detection of small currents or pulses that are created from the interaction of the tritium beta particles with the gas in the detector. Because of the low energy $\left(E_{\max }=18.6 \mathrm{keV}\right)$, the tritium beta has a very short range in most materials ( $5 \mathrm{~mm}$ in air, $5 \mu \mathrm{m}$ in solids). Windows in the detectors are not practical, and the tritium-bearing gas must be passed through the detector. Gas-filled detectors for 
tritium measurement are of three types, categorized by the voltage applied across the electrodes within them.

Table 2. Other specifications

Item

Specification

Manpower and personnel

Reliability and maintainability

Availability
Capable of being operated by existing shipboard personnel. Minimal operator training required using training manuals and/or videotape materials. Existing personnel capable of performing all organizational level and depot level repairs with existing equipment. Embedded computer for operator prompting is desirable.

High priority given to easily replaceable modules. $10,000-\mathrm{h}$ mean time between failures, $1 / 2$-h mean time to repair (organizational level), 1-h (intermediate level), self-check feature built in, 24-h mean logistics delay time.

\subsubsection{Ionization Detectors}

Ionization detectors consist of an electrically closed vessel containing an internal electrode. A voltage is applied between the wall of the chamber and the electrode producing an electric field, so the ionization produced by the tritium beta is collected as a current. The current is proportional to the internal radioactivity and independent of the electric field potential. The air that is passed into the chamber is filtered and trapped to remove particulates and other ionized species such as cigarette smoke. Since the detector is also sensitive to external radiation sources, two identical chambers are generally used, one to sample the tritium-bearing gas and one to detect the external radiation. This is referred to as gamma compensation. The two signals produced by these detectors are subtracted electronically to measure the tritium only.

The sensitivity and stability of a tritium ionization chamber are largely affected by the quality of the electrometer. Since the ionization current normally is so small, an electrometer is used to indirectly measure the ionization current by measuring the voltage drop across a series resistance. Since electrometers are so sensitive and the current output is so small, changes in temperature can affect the output signal, especially at low values of the ionization current. The cooler the electrometer temperature, the better the 
sensitivity. With present insulators within the detector and electrometers, ion chamber currents can be reliably measured down to about $10^{-13} \mathrm{~A}$. This effectively sets a lower detection limit of a small (about 1-2 L) ionization chamber.

Many electrometers are contained in a section of the housing that is hermetically sealed, containing a small quantity of silica gel desiccant. The desiccant serves to keep the housing and the electrometer very dry. A dry electrometer is important to its stability.

Detection limits are reduced based on the detector's environment. The detection limit for tritium in the presence of a high-energy beta emitter ${ }^{4}$ is

$$
\mathrm{C}_{\mathrm{T}}=0.5 \cdot \mathrm{C}_{\mathrm{HE}}^{1 / 2} \text {, }
$$

where $C_{T}$ is the minimum detectable concentration of tritium in microcuries per cubic meter (defined as that concentration for which the signal is three times the standard deviation of the noise) and $\mathrm{C}_{\mathrm{HE}}$ is the concentration of high-energy beta emitter, in microcuries per cubic meter.

Thus, taking into account the background radon in the air and radiation background present at the Oak Ridge National Laboratory (ORNL) tritium facilities, this limit is $\sim 1 \mu \mathrm{Ci} / \mathrm{m}^{3}$.

The detection limit of ion chamber systems can generally be decreased by increasing the size of the chamber. This increases the amount of current flow because there is more tritium present to cause ionizations to occur. Larger detectors are inherently longer in responding to changes in the inlet concentration, or they require higher sampling rates. Another way to decrease the detection limit is to increase the time constant (or the time that the detector electronics counts the detector) for the system.

A third method for increasing sensitivity of the detector, especially in the presence of high-energy beta emitting radionuclides or radon, is transmitting the sample through a semipermeable membrane such as Nafion (copolymer of tetrafluoroethylene and perfluorosulphonic acid) or dimethyl silicone. The key to this separation is the very high solubility of water in these materials, which results in higher permeation rates than common interfering species. The removal of these interfering species reduces the counting background within the detector and allows a higher sensitivity for tritium.

Field experience at ORNL has shown that the best reliable sensitivity of any ionization chamber system is about $5 \mu \mathrm{Ci} / \mathrm{m}^{3}$. If the ion chamber system ever detects a high level of tritium, the detector becomes contaminated (memory effect) and thus loses sensitivity for low-level tritium measurement. Polishing the internal surfaces or heating the ion chamber reduces this but does not eliminate it. Use of an autozero function (taking the present steady state signal and automatically calling it zero) tends to reduce sensitivity of the detector as the system ages. Tritium can also diffuse into the compensation chamber, further decreasing sensitivity.

\subsubsection{Proportional Detectors}

Proportional detectors are similar in principle to ionization detectors but have a higher electric field potential. This causes acceleration of the electrons/ion pairs, 
resulting in the production of secondary electrons from collisions with neutral gas molecules. The ions produced by single beta absorption therefore are counted in the form of a pulse. This multiplication is linear with respect to beta energy. Therefore, the total quantity of ionization (pulse height) is proportional to the initial beta energy, and the number of events (pulse rate) is proportional to the quantity of tritium present. This technique is more sensitive to low levels of tritium in the sample because electronic discrimination of higher energies than the $18.6-\mathrm{keV}$ beta of tritium is possible. Proportional detectors can be sensitive to tritium at concentrations as low as 0.001 $\mu \mathrm{Ci} / \mathrm{m}^{3}$. Gamma background can also be electronically discriminated, eliminating the need for compensation detectors. Unfortunately, air is an unsatisfactory counting gas. This is because it forms a high proportion of negative ions instead of electrons, resulting in a detector that is slow responding and is also affected by the humidity. Therefore, a gas such as methane, ethane, or a mixture of other gases such as methane-argon is generally used in these detectors.

\subsubsection{Geiger Tubes}

Geiger tubes have been used to detect tritium. ${ }^{5}$ As in the case with proportional detectors, the tritium sample must be introduced directly into the detector, and using air as the counting gas is unsuitable. These devices are event counters and are useful where only tritium is present. Generally, the sample is introduced into the detector and the

sample counted. It is difficult to discriminate against background radiation, so compensating Geiger tubes would be required.

\subsection{SCINTILLATION DETECTORS}

The interaction of radiation with certain crystals such as sodium iodide and anthracene causes the emission of light photons. These light photons can be detected with photomultiplier tubes. For tritium, since the beta range is in the submicron levels in solids, the sample must be placed inside the scintillator material, or a very thin solid scintillator must be used.

\subsubsection{Liquid Scintillation Detectors}

Liquid scintillator materials have been developed which are very well suited to low-level tritium detection. This is the preferred technique for counting swipe samples for contamination monitoring and for personnel monitoring by urinalysis. These monitors have also been used for wastewater flow monitors. In the liquid scintillation technique, a sample is placed within a scintillation cocktail that emits light photons that are counted with a photomultiplier-based counting system. Automatic counters are commercially available. Although some scintillation cocktails can be carcinogenic, effective biodegradable cocktails have been developed. Unfortunately, this technique produces a waste stream consisting of the used scintillation cocktail. 


\subsubsection{Solid Scintillation Detectors}

Because of the short range of the beta particle, solid scintillators are of limited usefulness in tritium detection. Plastic scintillators have been used for the detection of tritium. The form of these plastics has the scintillator material either embedded in or coated on transparent beads, plates, or fibers. These are optically coupled to photomultiplier tubes. These detectors have been used for both water and air tritium monitors and have roughly the same sensitivity as ionization chamber detectors. Detectors using polyethylene sheet and europium-doped calcium fluoride have been developed.

\subsection{SOLID STATE DETECTORS}

Surface barrier detectors have been used to detect $X$ rays resulting from tritium beta interaction with the dead layer in the detector; however, the sensitivity of this technique makes this a good tritium process monitor but is not sensitive enough for use as an environmental monitor.

\subsection{FORM DISCRIMINATING DETECTORS}

Detection of tritium in the presence of other radionuclides (such as ${ }^{41} \mathrm{Ar},{ }^{85} \mathrm{Kr}$, or ${ }^{222} \mathrm{Rn}$ ) is a particular challenge since the radiations of these species are all greater in energy than tritium. Detector response from radiation from these species generally masks detector response from tritium. To prevent this, tritium is separated from the other nuclides. A membrane such as Nafion is used to preferentially diffuse the tritium oxide in a gas stream into another carrier gas, which is then detected using an ionization detector. Other gaseous species do not diffuse readily through the membrane. This technique is also useful in discriminating between tritium in the oxide and elemental forms, since the latter does not readily diffuse through the membrane. The requirements for this field application did not include any requirements for the discrimination of other radionuclides in the sample or for the discrimination between the two forms of tritium.

\subsection{TRITIUM SAMPLERS}

Sometimes tritium detection is done off-line with sampler systems. This type of monitoring generally requires a laboratory-type system for counting, but some of the techniques used could apply to the problem at hand.

\subsubsection{Passive Samplers}

Various types of passive samplers have been developed ${ }^{1,6,7}$ for sampling tritium. The most simple of these is a vial that contains a small quantity of water or other sorbent, fitted with a lid that contains an accurate diffusion orifice (or tube) in the center. The 
theory behind this device is the basic gaseous diffusion process. If there are two regions of different molecular gas concentrations that are connected through a tube, the transport rate of gas from the higher to lower concentration is controlled by the physical parameters of the tube if the diffusion coefficient is constant. According to Fick's law, linear flow through the tube occurs if the concentration gradient between the two regions is maintained. This is subject to significant deviation depending on the airflow across the sampler tube. Absorbent materials in the sampler can be silica gel, anhydrous ethylene glycol, or a mixture of ethylene glycol and water.

The sampler is placed at the sample location and allowed to equilibrate with the airborne tritium oxide (HTO) suspected to be in the atmosphere for a specific time period. A 4- to 6-week exposure time is used, which depends on the expected air concentration and desired collection quantity of water. The exposure time is controlled by the size of the orifice on the sample vial and can be decreased by increasing the diffusion tube diameter. Airborne HTO diffuses into the vial and dissolves in the sorbent. At the conclusion of sampling, the vial is removed, and a liquid scintillation cocktail is added. The vial is placed into a liquid scintillation counter and is counted directly. Calculations are then made which relate the level of tritium in the solution to the air concentration, based on the sampler flow rate calculated from theory.

\subsubsection{Active Samplers}

Active samplers can use ethylene glycol or water or a solid such as silica gel. With this technique, a sample stream is drawn through a series of small bubbler vials where the water in the sampled stream equilibrates with the liquid in the bubbler. Periodically, the liquid in the bubblers is replaced, and the removed liquid is counted with a liquid scintillator. A heated tube with palladium or platinum catalyst in it can be used between two separate sampler trains in series to determine the relative quantities of tritium in the oxide and elemental form. This detector type is available commercially.

\subsection{SAMPLE ENRICHMENT TECHNIQUES}

The following is a discussion of the techniques for detecting tritium with environmental monitoring techniques, where the sample must first be enriched in tritium prior to measurement.

\subsubsection{Electrolysis}

In the measurement of environmental levels of tritium at sample concentrations above 50 tritium units ( $\mathrm{TU}, 1 \mathrm{TU} \approx 1.6 \mathrm{pCi} / \mathrm{L}$ ), direct counting techniques are used. These involve chemically reducing the hydrogen in a water sample to elemental form, followed by catalytic reaction with ethylene to produce ethane. The tritium content in this gas is then measured in a carefully calibrated proportional counting system. Determinations of tritium content below about $50 \mathrm{TU}$ requires enrichment of the sample prior to counting. This has been done by electrolysis and is practical because of the large separation factor 
achieved. The technique is to mix the sample water with a nonhydrogen-containing electrolyte in an electrolytic cell and then to reduce the volume by a factor of 20 by electrolyzing the water.

Theoretical considerations predict that the quantity of tritium contained in the residual solution $(\mathrm{N})$ is related to the residual volume of solution $(\mathrm{V})$ by the expression ${ }^{8}$

$$
\mathrm{V}_{\mathrm{f}} / \mathrm{V}_{0}=\left(\mathrm{N}_{\mathrm{f}} / \mathrm{N}_{0}\right)^{\beta},
$$

where $\beta$ is the separation factor and 0 and $f$ are initial and final conditions. The hydrogen in the water of the concentrated solution is then converted to ethane for proportional counting, as described above.

This particular volumetric technique is unsuitable for application outside the laboratory; however, it could be possible to design a flow-through cell that continuously enriches a sample for counting in another type of detector such as an ionization chamber or plastic scintillator.

\subsubsection{Adsorption and Chromatography}

Vapor pressure differences can sometimes be realized by adsorption of molecules on solid active surfaces such as charcoal, silica, alumina, and molecular sieves. ${ }^{2,9,10}$ Adsorption in this manner is the basis for separation of many classes of compounds and has also been reported in the separation of $\mathrm{H}_{2}, \mathrm{HT}$, and $\mathrm{T}_{2}$ mixtures. Success has been reported with molecular sieves at liquid nitrogen temperatures for small quantities of these gases for analytical purposes. Application to the present problem would involve extracting the hydrogen in a water sample and passing it through an adsorption column using a carrier gas. Tritium, which is more strongly adsorbed than protium, would concentrate on the column. Periodically, this adsorption process would be stopped and the adsorbent eluted with the carrier gas through a detector. The hydrogen eluted would be enriched in tritium, which would be detected in an ionization chamber or plastic scintillator. The column (or columns) could be cycled to provide continuous detection.

\section{TRITIUM MONITORS DEVELOPED FOR SPECIFIC APPLICATIONS}

The tritium monitors discussed in this section were all developed around specific applications but are not available commercially. They are listed for their potential applicability.

\subsection{GAS FLOW PROPORTIONAL COUNTER}

This detector ${ }^{11,12}$ was developed for the measurement of tritium concentrations in situ in a well or borehole. The instrument is designed to detect tritium at levels as low as 
terrestrial background, and it purifies the sample from other radionuclide and chemical contaminants. Air sampling is done by passing the sample over a palladium catalyst together with a small amount of carrier hydrogen to convert all tritium to the oxide form. The water is collected in a cold trap that is cooled thermoelectrically. The sample is removed from the cold trap in a batch mode and converted to hydrogen by passing through a magnesium bed at $1000^{\circ} \mathrm{F}$. The sample hydrogen is passed to a gas proportional counter, which is surrounded with a shield counter that is filled with the same counting gas as the tritium chamber. The pressure is adjusted to $2 \mathrm{~atm}$ with ethane or propane, and the gas is counted. Counting is done using the anticoincidence mode (coincident counts in the shield and tritium counters are ignored) to reduce gamma background. Radiations of energy greater than the $18.6-\mathrm{keV}$ maximum tritium energy are discriminated against electronically.

The sensitivity of this instrument was demonstrated to be about $50 \mathrm{pCi} / \mathrm{mL}$ water. This is equivalent to about $5 \times 10^{-4} \mu \mathrm{Ci} / \mathrm{m}^{3}$ in $25^{\circ} \mathrm{C}$ air at $50 \%$ relative humidity.

\subsection{PLASTIC SCINTILLATOR}

Plastic scintillator detectors have been investigated for use in various applications at several different sites ${ }^{13-22}$ with some success, for both air and water monitoring. Several of these are described below.

A plastic scintillator monitor ${ }^{13}$ was developed at Chalk River Laboratory (CRL) for the detection of tritiated water vapor in air at locations near heavy water reactors with normal gamma fields. The detector consists of two strips of plastic scintillator with a 1-mm gap between them about an inch wide rolled together in a double spiral. Air flows in the space between the two strips at a sample rate of $5 \mathrm{~L} / \mathrm{min}$. The ends of the spiral are optically coupled to two photomultiplier tubes. To discriminate between signal and noise pulses, a coincidence counting system is used. Since pulses from gamma radiation are a significant portion of the total signal from the detector, the detector is shielded, and two additional channels of coincidence-anticoincidence electronics are used. The gamma compensating electronics were incorporated to allow lower tritium detection limits and to enable the detector to distinguish tritium from gaseous fission products. Under ideal conditions, this instrument can detect $1.5 \mu \mathrm{Ci} / \mathrm{m}^{3}$ tritium in a $1-\mathrm{mR} / \mathrm{h}$ gamma field.

Another detector ${ }^{14}$ was developed at CRL, as follow-on work, for the monitoring of tritium in water. This detector consisted of a series of plastic scintillator sheets mounted vertically and spaced $0.075 \mathrm{~cm}$ apart to form a cell. Two photomultiplier tubes were placed at opposite sides of the cell and were counted with a single channel analyzer and coincidence counting system. This detector was also tested for detection of tritium in air. It has a sensitivity of about $1 \mu \mathrm{Ci} / \mathrm{m}^{3}$ for tritium in air in a $1-\mathrm{mR} / \mathrm{h}$ gamma background.

Plastic scintillation monitors have also been developed for monitoring tritium at the Bhabha Atomic Research Center (BARC) in India. ${ }^{15-17}$ These monitors were developed for detection of water leakage from heavy water reactor systems. The detector consists of about 200 thin $(6-\mu \mathrm{m}$-thick) films of plastic scintillator material packed into a 
cell that forms into a sponge during use. The detector cell is optically coupled to two photomultiplier tubes, which are counted with a coincidence counting system. The sensitivity of this system for tritiated water is $3.7 \mathrm{kBq} / \mathrm{L}(0.1 \mu \mathrm{Ci} / \mathrm{L})$; the system has been in operation since April 1984.

Tritium-in-air monitors using the same principle were also developed at BARC. This monitor system is based on the tritium-in-water detector previously developed and has been refined by using a sample equilibration system to transfer the tritium in the atmospheric moisture to a liquid phase for counting with the tritium-in-water detector described above. This technique was preferred over a condensation technique because previous experience with such a monitor indicated that it was slow responding. To increase the response of this monitor, an increase in sampling rate, condensation rate, and the resultant refrigeration would have been required. The exchange method was first proposed by Osborne of $\mathrm{CRL}^{18}$ and is used there as a technique for removing noble gases from the sample.

The Savannah River Plant has plastic scintillator monitors ${ }^{19-21}$ for process control and aqueous effluent monitoring under development. The goal of the research is to produce a process monitor that can detect $37 \mathrm{kBq} / \mathrm{L}(1 \mu \mathrm{Ci} / \mathrm{L})$ tritium in water and a liquid effluent monitor that can detect $1 \mathrm{kBq} / \mathrm{L}(0.03 \mu \mathrm{Ci} / \mathrm{L})$. Solid scintillator beads appear to be the most promising detector for this application. Plastic scintillator fibers were also studied, and these appeared to be adequate though less efficient than the beads. Experiments are continuing to optimize the configuration of these plastic scintillators and to develop new scintillators for improved tritium detection.

A tritium monitor was developed at Savannah River and is presently being used as an effluent monitor for the production reactors. This monitor was originally a laboratory instrument but was made into a field unit after a tritiated water release incident. The monitor is designed to provide early detection of a small leak of heavy water moderator at the $\mathrm{K}$-Reactor and to facilitate rapid isolation procedures. The tritium detector consists of an analysis cell containing 0.1 - to 0.25 -mm-diam beads of plastic scintillator interposed between two photomultiplier tubes and coincidence electronics. The detector is shielded to reduce background, and discrimination of higher energies than tritium is done electronically. A small portion of the effluent stream is processed through a water purification system consisting of filters, an ion-exchange column, and an activated charcoal column before entering the detector. The monitor will alarm if the tritium concentration in the water exceeds $56 \mathrm{kBq} / \mathrm{L}(1.5 \mu \mathrm{Ci} / \mathrm{L})$.

A second-generation monitor was developed at Savannah River. This monitor was designed around a commercial wastewater monitor, a Berthold LB-507A, but uses a different plastic scintillator material. It has a sensitivity of about $25 \mathrm{kBq} / \mathrm{L}(0.67 \mu \mathrm{Ci} / \mathrm{L})$. The system has a fully automated water purification system consisting of filters; an ultraviolet sterilizer; activated charcoal column; and cation, anion, and mixed-bed ion exchange columns in addition to the radiation detection system and data acquisition and analysis system that are interfaced to plant alarms. The water purification is required to reduce bioluminescence and chemiluminescence that occur in these systems. In addition to the real-time monitor, Savannah River also collects a composite water sample from the same system which is analyzed on an 8-h basis, as well as collecting the water that passes 
through the detector for analysis on a daily basis. These serve as a cross check to the realtime monitor.

A detector could possibly be developed as an extension of the above monitor for detection of tritium in air, with the use of a fiber scintillator arrangement for high surface area. A proposal has been made by Savannah River to the Department of Energy (DOE) to begin development of such a monitor, but funding has not yet been approved.

A plastic scintillator called the Solenoidal Detector Collaboration (SDC) detector $^{22}$ was being developed for the Superconducting Supercollider (SSC) project as one of the competing concepts for the very large particle detectors. This detector was a tracking detector for high-resolution charged particle tracking and would have been an extremely large detector system. The detector elements were to be composed of $830-\mu \mathrm{m}-$ diam scintillating fibers that were optically coupled to clear waveguides for transmission of the light to a photodetector. The photodetectors of choice were to be visible light photon counters (VLPCs) developed for their superior count rate capability. Although this system is unsuitable for tritium monitoring (tritium monitoring requires very small diameter fibers and the low levels do not require high count rate capability), the fiber technology, detector technology, and counting techniques could be applicable.

\subsection{AVALANCHE PHOTODIODE DETECTOR}

Low-noise silicon avalanche photodiodes ${ }^{23,24}$ (APDs) with ultra thin surface dead layers have been developed for detecting tritium beta particles. Unlike present windowless proportional counters and liquid scintillation techniques, this detector requires no liquid or flowing gases. The APD's primary attraction is the superior compactness and ability to sense directly low-energy beta particles. The APD also exhibits an internal gain, which other solid state detectors do not.

The APD is a p-n junction formed in a silicon wafer. The structure consists of an upper surface, drift region, space charge region, and substrate. A particle detector is configured to minimize the thickness of the dead layer, thus increasing the sensitivity of the device at the surface. When beta particles of greater energy than the $1.1-\mathrm{eV}$ bandgap of silicon are absorbed in the silicon, electron-hole pairs are generated. If a pair is generated in the drift region, there is a high probability that the minority carrier will be captured in the space charge region, thus contributing to the current flow. Since the device may be operated at near breakdown voltage under reverse bias, a large electric field $\left(\sim 10^{6} \mathrm{~V} / \mathrm{cm}\right)$ is created in the space charge region. Electrons generated by energy absorption in the drift region migrate toward the space charge region, where they are accelerated by the large electric field. They gain sufficient velocity to cause additional ionization, thereby providing the internal gain mechanism. An APD is designed to operate at a gain of $100-150$.

The sensitivity of this detector for tritium has been measured to be about 33 $\mathrm{Bq} / \mathrm{cm}^{2}$ using a tritium polymer source. The equivalent concentration in air is about 4000

$\mu \mathrm{Ci} / \mathrm{m}^{3}$. The counting efficiency measured was about $15 \%$. The detector must be placed in the dark because it is also extremely sensitive to visible photons. 
An alternate use of a detector such as this is to observe the bremsstrahlung produced by the interaction of the tritium beta with an absorber. In this case, the detector remains outside the process system, separated by a thin window. Since roughly one X ray is produced for every $10^{4}$ beta particle/absorber interactions, this technique is limited to process applications where the tritium concentration is above $1 \mathrm{Ci} / \mathrm{m}^{3}$.

\subsection{ELECTRET ION CHAMBER}

Electret ionization chambers ${ }^{25}$ (EICs) have been used for several years as passive monitors for $\mathrm{X}$ - and gamma radiation. The recent commercial availability of stable electrets has made the use of this type of detector a practical alternative.

An EIC is an integrating ionization chamber wherein the electret (a charged Teflon disk) serves as both the electrostatic field and as a sensor. It consists of an electret mounted inside a small chamber made of conducting plastic. The ions produced inside the chamber are collected on the electret. The reduction in charge is a measure of the total ionization produced during the time the chamber is exposed. The charge is measured by a portable voltage meter. This device is passive in nature and can be thought of as being analogous to a direct-reading pocket dosimeter.

A practical unit for tritium detection has recently been developed and was shown to have a sensitivity of 0.4 derived air concentration-days $\left(\sim 8 \mu \mathrm{Ci} / \mathrm{m}^{3}\right)$.

\section{EXISTING COMMERCIALLY AVAILABLE TRITIUM MONITORING SYSTEMS}

There are eight known vendors of tritium monitoring instruments in the United States and Canada. A discussion of six of these companies together with their off-theshelf instrumentation is given below. All of these companies have the capability to make specially designed tritium monitors. These six companies were all sent a copy of a preliminary specification (Appendix B) and were asked to make an evaluation of this specification as to whether their company could manufacture a tritium monitor such as this. They were also asked to respond with a preliminary proposal (what the monitor would consist of, list of features that it would have, etc.) together with a budgetary estimate of cost. They were also asked to determine whether they could meet all specified requirements, to indicate which requirements they could not meet, and to offer an alternative to those requirements. The responses to this exercise are listed below along with data on the companies. 


\subsection{BECTON DICKINSON DIAGNOSTIC INSTRUMENT SYSTEMS}

This company is a large (\$50-100 million/year) manufacturer of medical and laboratory equipment, including diagnostic instruments for analytical laboratories. The tritium monitoring instrumentation capability was acquired from a company called Johnson Laboratories several years ago.

There are two models of tritium monitors available off-the-shelf. The specifications of these are listed in Table 3. These monitors are of the compensated ionization chamber type.

Table 3. Becton Dickinson tritium monitors

\begin{tabular}{lll}
\hline & $955 \mathrm{~B}$ & $\underline{11}$ \\
Model No. & 10 & 4 \\
Flowrate, $\mathrm{L} / \mathrm{m}$ & 10 & 0.8 \\
Detector air volume, $\mathrm{L}$ & 0.2 & 1 \\
Detection limits, $\mu \mathrm{Ci} / \mathrm{m}^{3}$ & $\mathrm{To} 5 \mathrm{mR} / \mathrm{h}$ & To $5 \mathrm{mR} / \mathrm{h}$ \\
Gamma compensation & $0-10$ & $0-50(\mathrm{linear})$ \\
Ranges, $\mu \mathrm{Ci} / \mathrm{m}^{3}$ & $0-100$ & $0-500(\mathrm{linear})$ \\
& $0-1000$ & $10^{1}-10^{4}(\mathrm{log})$ \\
& $0-10,000$ & $10^{3}-10^{6}(\mathrm{log})$ \\
Time constant & 15 and $45 \mathrm{~s}$ (selectable) & $20 \mathrm{~s}(0-50 \mathrm{scale})$ \\
Accuracy & \pm 10 of full scale & \pm 10 of full scale \\
& \multicolumn{2}{c}{$($ linear) } \\
Reproducibility & $\pm 2 \%$ & \pm 20 of full scale (log) \\
Zero drift & $\leq 2 \%$ (full scale) $/ \mathrm{d}$ & $\leq 1$ least significant \\
Calibration & Calibrated with gas calibrator CL-1, $4 \mu \mathrm{Ci} / \mathrm{m}^{3}$ \\
& $( \pm 10 \%)$ tritium in nitrogen \\
\hline
\end{tabular}

These monitors appear to be suitable for this application, but neither monitor gives adequate detection limits for the required accuracy. The off-the-shelf monitors probably cannot meet the MIL-spec standards. These monitors suffer the same limitations of any other ion chamber system, namely, that its claimed sensitivity $(0.2$ $\mu \mathrm{Ci} / \mathrm{m}^{3}$ ) has not been achieved in the field. ORNL has experience with both of these monitors and had found them to be easily calibrated and reliable in the field. Generally, 
the monitors' capabilities are not overstated, but it is questionable that this monitor system can measure the required sensitivity.

\subsubsection{Response to Proposal Request}

Becton Dickinson responded to the proposal by rewriting the specification they received to match what they could produce. This specification differed from the proposal in the following points.

A sensitivity of $0.2 \mu \mathrm{Ci} / \mathrm{m}^{3}$ in a $5-\mathrm{mR} / \mathrm{h}{ }^{60} \mathrm{Co}$ background at an accuracy of $\pm 10 \%$ at the $95 \%$ confidence level is quoted. They do not have at present any information about monitor performance in a neutron background. The proposed MIL standards shock tests have not been applied to the monitor design. The monitors cannot detect tritiated particulates. The EMI noise immunity capability of the monitor is questionable. An embedded computer is not available.

The proposed monitor is written around the company's model 955B monitor system. The detector size is $10 \mathrm{~L}$, which does not make the monitor all that large (19-5/8 $\times 14-3 / 4 \times 21-5 / 8)$ or heavy $(67 \mathrm{lb})$. If they could design the monitor to meet the shock requirements, then the standard system would be very close to the desired specification.

\subsection{EG\&G NUCLEAR INSTRUMENTS DIVISION}

This company is a division of EG\&G and is an amalgamation of four international companies. They are Laboratorium Prof. Dr. Rudolf Berthold, Wildbad, Germany; Benelux Analytical Instruments, Vilvoorde, Belgium; EG\&G ORTEC, Oak Ridge, Tennessee; and EG\&G Labserco, Oakville, Ontario, Canada. The Berthold company manufactures the tritium monitor and also engineers and manufactures measuring instruments and radiation protection systems. It has a staff of 350 employees.

Two monitors are available, both of which can measure low tritium levels. The first, described below, is a proportional counter (Model LB-110), and the other is a tritium bubbler (Model EL-700) that uses anhydrous ethylene glycol for tritium oxide absorption. This monitor incorporates a heated catalyst bed for elemental tritium conversion, thus allowing the discrimination between the elemental and oxide forms of tritium. The liquid in the bubblers is removed periodically and counted with a liquid scintillation counter. With an 8-h sample time, the monitor has a detection limit of $0.0005 \mu \mathrm{Ci} / \mathrm{m}^{3}$.

The proportional counter monitor is a third-generation system for measuring the tritium content of room and exhaust air. The detector is a 1.3-L proportional counter that requires a 1:3 mixture of air:methane for operation. The system can also use P-10 gas (90\% argon, 10\% methane), though a larger quantity (1:4) is required and at a lower detector sensitivity. However, the $\mathrm{P}-10$ has the advantage that it is noncombustible.

The monitor uses pulse rise time discrimination for gamma and other radionuclides (primarily noble gas). Pulse rise time is dependent on the different drift times of secondary electrons generated in the ionization process as they travel to the 
counting wire. The shorter the range of the beta particle, the smaller the average fluctuation of the arrival time at the counting wire, leading to shorter rise times. Since tritium has such a low average energy beta, it is relatively easy to isolate pulses that originate from tritium betas from those resulting from gamma or other nontritium betas.

The electronics incorporate a fast (10-ns) charge sensitive preamplifier followed by a voltage amplifier. The signal is passed through a double delay line pulse shaping network zero crossing discriminator. The pulse width is a measure of rise time. A pulse width discriminator sorts the pulses into two channels, one for tritium and the other for gamma and noble gases. Three types of data processing, display, and recording systems are available, two of them microprocessor-based.

Either monitor gives adequate detection limits for the required accuracy; however, the bubbler sampler does not give real-time output of tritium concentration. The use of counting gas in the proportional counter is a drawback since some shipboard applications do not have a ready exhaust available. Consumption of P-10 gas, preferable since it is noncombustible, is about $12 \mathrm{lb}$ per week. Application of these monitors would therefore be difficult for those locations that are not able to provide an exhaust for the gas mixture. If methane were used, the gas mixture could be catalytically burned and the resulting $\mathrm{CO}_{2}$ removed with existing $\mathrm{CO}_{2}$ removal systems. In a closed shipboard environment, the use of methane could be dangerous, and if this catalytic burner equipment were to fail, it could contribute $\mathrm{CO}$ to the local environment if it burned incompletely.

The performance specifications of this detector system are listed in Table 4.

Table 4. EG\&G Berthold tritium monitor, Model LB-110

\begin{tabular}{lll}
\hline & $\underline{\text { Methane }}$ & $\underline{\mathrm{P}-10}$ \\
Flow rate (air/methane), $\mathrm{L} / \mathrm{min}$ & $1 / 3(0.25 / 0.75)$ & $1 / 4(0.25 / 1.0)$ \\
Measuring air volume, $\mathrm{mL}$ & 325 & 260 \\
Efficiency, \% & 60 & 55 \\
Background rate, cps & $1-3$ & $1-3$ \\
Spillover to tritium channel $\left({ }^{137} \mathrm{Cs}\right), \%$ & $5-7$ & $5-7$ \\
Spillover to tritium channel $\left({ }^{85} \mathrm{Kr}\right), \%$ & $3-5$ & $3-5$ \\
Spillover to tritium channel $\left({ }^{14} \mathrm{C}\right), \%$ & $23-25$ & $23-25$ \\
Measuring time/ & & \\
detection limits ${ }^{a}\left(\mu \mathrm{Ci} / \mathrm{m}^{3}\right)$ & & \\
$\quad 30 \mathrm{~s}$ & 0.11 & 0.15 \\
$1 \mathrm{~min}$ & 0.076 & 0.1 \\
$10 \mathrm{~min}$ & 0.024 & 0.035 \\
$1 \mathrm{~h}$ & 0.011 & 0.013 \\
$24 \mathrm{~h}$ & 0.002 & 0.003 \\
\hline
\end{tabular}

${ }^{a}$ Detection limit values are calculated for 2-cps background and 3- $\sigma$ error. 


\subsubsection{Response to Proposal Request}

EG\&G responded to the request for proposal by recommending a new detector system that they are marketing. This is an ionization-chamber-based detector system. The Model LB 6710-2H Ionization Chamber has a 2-L volume with a heated chamber. Design features of the detector are intended to make the unit more rugged, more stable in high and fluctuating environmental temperatures, and less subject to external electromagnetic influences. This is a departure from what this company is known for, and the description of this monitor system is given below.

The ionization chamber design is such that it is easy to scale up or down the detector volume. The chamber is constructed of two concentric cylinders that can be modified in length. These chambers are mounted on a machined block made of stainless steel. Sample inlet and outlet are machined into the block. The sample air passes through the inlet and into the annular space between the inner side of the outer cylinder (which is at ground potential) and the outer side of the inner cylinder. This inner cylinder is raised to the polarizing voltage of $+40 \mathrm{~V}$ by the lithium batteries (located on the electrometer board). In addition to generating the ionization chamber bias, the voltage on the inner cylinder creates a preliminary field between the two cylinders which serves to precipitate some of the radon/thoron daughters that have managed to evade the mechanical filter, thus eliminating a source of background interference. The air then passes into the inner cylinder, where any ionization current is collected at the electrode. The detector is very leaktight to allow use in primary process loops. Special Teflon insulators for the measuring electrode and feed-through insulators and O-rings for the other supplies are part of the construction. The detector must be able to be heated. Heating wire wrapped around the measuring volume reduces the possibility of tritium oxide adsorbing to the chamber wall.

The electrometer is extremely stable and has low temperature dependence. These characteristics are accomplished using a laser-trimmed high-quality circuit integrated in the electrometer stabilized at a constant temperature with a Peltier cooler. The electrometer circuit board is contained in a section of the housing that is hermetically sealed. The housing contains a small sachet (actually, a hollow-core screw) with a silica gel desiccant. When the chamber is ready to be sealed (either after manufacturing or maintenance), the hollow screw is packed with new desiccant and the housing is sealed. The polarizing bias voltage is provided by lithium iodide batteries. These batteries have a 5-year lifetime. In this design, no EMI can penetrate the front end of the electrometer.

The outstanding points for the stability of the circuit are that (1) the electrometer chip is of high quality with extremely low bias current and offset voltage and that (2) the electrometer resides in a metal housing that is maintained at a constant temperature by a Peltier diode. The temperature control circuit supplies a current to the Peltier diode as a function of the voltage over the high-temperature conductor that resides in a small aluminum block between the Peltier element and the electrometer chip. This serves to cool the electrometer. The output of the electrometer is proportional to the ionization current in the chamber and is largely stable and independent of external factors. The circuitry is provided with an alarm comparator that will signal an alarm condition whenever the temperature of the electrometer deviates from the set value. If the 
electrometer should drift toward a positive voltage, the deviation is detected by the electrometer failure comparator and signaled as such.

The system has a pulse output that can be connected to a standard transistortransistor logic (TTL) input of a counter. The voltage-to-frequency converter receives the signal from the electrometer circuit and converts it to a pulse train. The output of the electrometer is a negative-going signal and is zeroed in such a way that the output is always slightly negative even in the case of no activity. This signal is inverted and fed to the filter circuit as well as the electrometer failure circuit. The output of the detector is a standard positive pulse with a 50/50 duty cycle and an amplitude of $6 \mathrm{~V}$ into a $50-\Omega$ load.

The detector measuring range can be changed. A second range resistor in the electrometer is selected by an electromagnetically operated glass-reed relay. The detector circuitry outputs a train of pulses, which is 0 to $10 \mathrm{kHz}$ for an ionization chamber current of $10 \mathrm{pA}$ to $1 \mathrm{nA}$. In the case of the $\mathrm{LB} 6701-2 \mathrm{H}$, the 0 to $10 \mathrm{kHz}$ represents a maximum activity of $8.1 \times 10^{3} \mu \mathrm{Ci} / \mathrm{m}^{3}$ in the low range and $8.1 \times 10^{5} \mu \mathrm{Ci} / \mathrm{m}^{3}$ in the high range. When the pulse train reaches $10 \mathrm{kHz}$, the data system sends a $5-\mathrm{V}$ signal $(850-\mathrm{mA})$ to energize the range-change reed relay of the detector. This triggers the range change of the electrometer and a resulting 100-fold decrease in sensitivity, and the data system applies a new calibration factor to the pulse train. Hysteresis is built into the system to prevent range switching oscillations.

The detector is easily introduced into existing systems. Setup of the instrument can be accomplished via two methods: through the integrated front-panel keypad and through an RS232 interface and personal computer. In either case the setup is menu driven and provides the user with an easy facility for setting instrument alarm levels, acknowledging alarms, and recording of data.

A green "normal" lamp and a red "alarm" lamp are mounted on the instrument. The lights may be located on the instrument front panel or top or remotely located. An internal relay can be used to actuate remote alarms. Alarm set points are available for the entire measuring range.

The system includes a check source that may be remotely actuated or locally actuated. A test switch is also available for testing of audible and visual alarms. The detector is equipped with Kwik-Flange fittings for easy installation and replacement of the detector in the sample loop.

\section{3 femto-TECH, INC.}

femto-TECH is a small company in Carlisle, Ohio, that makes tritium monitors for general use, along with other types of detectors. The company was started by ex-DOE contractor employees.

Five compensated ionization chamber monitors are available, and they are just now marketing a scintillation-based detector. One of these monitors is a battery-operated portable model. Three of these monitors are designed for measuring the tritium concentration of glove-box atmospheres and in process applications (two ion chambers and the scintillation detector). The specifications of the monitors suited to room or duct 
air monitoring are given in Table 5. The ion chamber internals are all highly polished stainless steel, a technique that reduces internal contamination and therefore memory effects.

All monitors (except the hand-held unit) are controlled with the same microprocessor-based control unit. This unit contains the monitor power, display, alarm setting controls, zero offset, check and adjust controls, gamma compensation level controls, instrument functional test controls, data storage and communications, and outputs.

The ion chamber may be located up to $1000 \mathrm{ft}$ from the control unit without signal degradation. These monitors appear to be applicable for this application. The off-theshelf monitors probably cannot meet the ML-spec standard. These monitors suffer the same limitations of any other ion chamber system, namely, that its claimed sensitivity $\left(0.1 \mu \mathrm{Ci} / \mathrm{m}^{3}\right)$ has not been achieved in the field. Though ORNL does not have any experience with this company's monitors, it is questionable that this monitor system can measure the required sensitivity. Use of the autozero function tends to reduce sensitivity of the detector as the system ages.

Table 5. femto-TECH tritium monitors

\begin{tabular}{|c|c|c|c|}
\hline Model No. & $224 R M$ & $224 \mathrm{DU}$ & PTM-1812 \\
\hline Flow rate, $\mathrm{L} / \mathrm{m}$ & 20 & $\begin{array}{l}\text { Diffusion through } \\
\text { perforated wall }\end{array}$ & $\bar{a}$ \\
\hline Detector air volume, $\mathrm{L}$ & 1.8 & 1.8 & 0.18 \\
\hline Detection limits, $\mu \mathrm{Ci} / \mathrm{m}^{3}$ & 0.1 & 1 & 1 \\
\hline \multirow[t]{2}{*}{ Ranges, $\mu \mathrm{Ci} / \mathrm{m}^{3}$} & $0-2000$ & 0-2000 & $0-20,000$ \\
\hline & $0-2,000,000$ & $0-20,000,000$ & \\
\hline Accuracy & $\pm 5 \%$ of reading & $\pm 5 \%$ of reading & $\pm 5 \%$ of reading \\
\hline Zero drift & $\leq 1 \mathrm{LSD} /$ week $^{b}$ & $\leq 1 \mathrm{LSD} /$ week & $\leq 1 \mathrm{LSD} /$ week \\
\hline Calibration & \multicolumn{3}{|c|}{$\begin{array}{l}\text { Monitors are designed and fabricated to be identical to } \\
\text { prototypes that are calibrated with National Institute of } \\
\text { Standards and Technology (NIST) traceable tritium gas } \\
\text { standards. Field calibration is by gamma source. }\end{array}$} \\
\hline
\end{tabular}

${ }^{a}$ Monitor is supplied with two ion chambers, one perforated for passive sampling and the other solid for active sampling.

${ }^{b} \mathrm{LSD}=$ least significant digit. 


\subsubsection{Response to Proposal Request}

femto-TECH responded to the proposal by commenting on the preliminary specification point by point. They indicated that the specification gave a general description of desirable features for a tritium monitor but that much more detail concerning the specific use and functionality was required to accurately estimate the true cost of such a unit. They also suggested additional details that could be useful in defining the new instrument. While they do not presently offer a single monitor that has all of the items of the preliminary specification, they believe that they can manufacture a monitor that could. The only problems they indicated they had were meeting the ruggedness qualifications and performing the testing for multienergy neutron background. The size of the production lots will also significantly affect the end product cost since this is a highly specialized instrument. Comments on the specification are listed below.

Sensitivity:

Accuracy:

Operating Range:

Operating Background:

Calibration:

Response Time:

Alarm:
The ${ }^{60} \mathrm{Co}$ gamma background needs to be defined as constant or varying.

The accuracy should be defined as for the entire operating range (not just center range); $\pm 10 \%$ is closer to state of the art. This should also define the pressure range to maintain rated accuracy [such as $93-106 \mathrm{kPa}$ (700 to 800 torr)].

Is multirange with autoranging acceptable, or should this be single range [which would require an analog-to-digital converter $(\mathrm{ADC})]$ ?

An allowance for background buildup due to exposure to tritium needs to be defined.

$\pm 10 \%$ is closer to state of the art.

This should be defined to a 95\% confidence level. Typically, response time is proportional to flow rate since the electronics can respond in milliseconds.

The audible alarm needs to be defined for sound output (such as 80 to $90 \mathrm{~dB}$ at $2 \mathrm{ft}$ at $2900 \mathrm{~Hz}$ or 55 to $68 \mathrm{~dB}$ at 2 $\mathrm{ft}$ if quietness is a concern). The visual alarm should define if a light source such as a light-emitting diode (LED) is acceptable or if the instrument's main screen could flash the alarm. 
Ruggedness:

Self-check:

Detector Size:

Universal Detection:

Embedded Computer:

Modules:

Reliability:

Availability:
This is the toughest and most costly specification to comply with. MIL-S-1 defines that the item will meet the shock requirements without the use of resilient mountings installed between the equipment and the ship structure or foundation. This may not be applicable if this is to be a movable instrument. MIL-E- 16400 has been superseded by MILSTD-2036A, General Requirements for Electronic Equipment Specifications. According to Sect. 1.2, Use of this specification, "This standard shall not be invoked on a blanket basis in end-item specifications. Each requirement contained herein shall be tailored to the application of the equipment." (Highlighting from the specification.) To acknowledge compliance with this requirement without further detail is meaningless.

This should specify whether a nuclear check source is required or whether an electronic test is acceptable.

It is unclear as to whether this means "detector" or the whole instrument.

Replaceable filters may be required. Different gases can cause different calibrations. Typically, instruments with this operating range are calibrated in nitrogen or air. Also, any ionized gases are a potential source of interference and would require the use of a metal filter to eliminate.

This should define microprocessor or microcontroller based.

This should define whether desoldering is unacceptable and limit maintenance to simple hand tools.

$10,000 \mathrm{~h}$ is reasonable for the electronics but not realistic for the tritium exposed areas. If the detector is exposed to $10,000 \mu \mathrm{Ci} / \mathrm{m}^{3}$ for periods of time, the background (memory) will be greater than the low-alarm set level.

This needs further definition such as to whether the unit is self-contained or whether it receives electricity from an external source (such as a ship).

Additional questions pertaining to the instrument design and some suggested design details are listed in Appendix C. These are features that would normally be included in a specification. 


\subsection{OVERHOFF TECHNOLOGY CORPORATION}

The Overhoff Technology Corporation (OTC) has been in business for $\sim 20$ years and has supplied both fixed and portable tritium monitors to government and industrial consumers. Among these have been the military, nuclear power plants, ${ }^{26}$ radioactive waste facilities, hospitals, pharmaceutical companies, and watchmakers. They have had experience in the manufacture of monitors to $\mathrm{MIL}$ standards, and ionization chamber monitors are available in various shapes and sizes. This company is very flexible in tailoring the application of their equipment to any given set of requirements and began their business by building one-of-a-kind systems for DOE contractors. The off-the-shelf monitors described below are therefore only representative of what the company can produce. The necessary engineering expertise exists to modify an off-the-shelf system or to start from scratch to develop a new system that is specifically tailored to a given application.

The off-the-shelf models include the 300 and 400 series, which are available as a single range or multirange or with autorange switching. They can contain either single or dual ionization chambers that can be remotely or internally mounted. Additionally, heated ion chambers are available along with alpha suppression circuitry, autozero, several types of alarm systems, and various types of indicators such as digital or analog panel meters. Circuits for the connection to a remote monitoring system are also available.

Several newer monitors are available which use a membrane to remove ionized gases and other radionuclides from the sample, to ensure that only tritium is counted. This effectively reduces the detection limit of the monitor.

The specifications of the off-the-shelf monitors are listed in Table 6 .

The principal limitation to their equipment is that suffered by any other ionization chamber system, namely, that the claimed sensitivity $\left(0.01 \mu \mathrm{Ci} / \mathrm{m}^{3}\right)$ has not been achieved in the field. Use of the autozero function tends to reduce sensitivity of the detector as the system ages. Other sites have also reported experience with these monitors, as given in Refs. 23 and 24.

\subsubsection{Response to Proposal Request}

OTC indicated that they could now build a monitor to the specifications submitted with the exception of a few details. They responded with comments to each item in the specification. The comments that were exceptions to the specification are discussed below.

The sensitivity requirement is believed to be achievable with an ionization chamber cluster configuration, which OTC claims to reduce gamma response by a factor of 1000 . The accuracy requirement, if it is interpreted to mean the measurement of 0.1 $\mu \mathrm{Ci} / \mathrm{m}^{3} \pm 0.02 \mu \mathrm{Ci} / \mathrm{m}^{3}$, is not technically possible. What is possible is the ability to detect $0.1 \mu \mathrm{Ci} / \mathrm{m}^{3}$ within 1 or 2 standard deviations $(\sigma)$, with a $10-\mathrm{L}$ ion chamber and a 2min time constant. The response to a step increase requirement is not stated very well and was interpreted to mean a 2 -min $(63 \%)$ time constant. This is possible. The most 


\section{Table 6. Overhoff Technology tritium monitors}

Model No.

Detection limits, $\mu \mathrm{Ci} / \mathrm{m}^{3}$

Stability and noise

Long-term drift

Time constant

Flow rate, $\mathrm{L} / \mathrm{m}$

Detector air volume, $\mathrm{L}$

Number of detectors

Ranges, $\mu \mathrm{Ci} / \mathrm{m}^{3}$
300 and 400 Series

0.01

$<$ Least significant panel meter digit

Eliminated by autozero circuit

$2 \mathrm{~s}\left(>1000 \mu \mathrm{Ci} / \mathrm{m}^{3}\right)$

$5-10 \mathrm{~s}\left(80-1000 \mu \mathrm{Ci} / \mathrm{m}^{3}\right)$

$20 \mathrm{~s}\left(<80 \mu \mathrm{Ci} / \mathrm{m}^{3}\right)$

Depends on application

$0.02,0.2,0.5$, and 2 standard

Single or dual, depending on gamma

compensation requirements

Single, 3-6 decades

Multi, 3-10 decades (digital readouts must be range

switched either manually or automatically)

serious point is the ionization chamber size requirement. It is not believed that a standard (2-L) ion chamber could be made to measure $0.1 \mu \mathrm{Ci} / \mathrm{m}^{3}$ unless a long time constant were specified or high electronic noise were tolerated. A short time constant together with a low detection limit in a small ion chamber system are incompatible requirements. The requirement for universal detection of tritiated particulates as well as gases cannot be met with an ionization chamber since ion chamber instruments are seriously adversely affected by particulates. The other requirements do not pose any undue burden on this vendor and could be met. During the monitor design and procurement process, some of the requirements could be modified as better definition of the problem is achieved. Monitor performance in a neutron background would also have to be determined experimentally during the design phase.

In summary, if OTC built the tritium monitoring system, it would have a cluster of 10- $\mathrm{L}$ ion chambers that could detect $0.1 \mu \mathrm{Ci} / \mathrm{m}^{3}$ at $2-\sigma$ accuracy with a 2-min time constant but could not detect tritiated particulates.

\subsection{SCINTREX LIMITED}

This company is Canadian and has been in business since 1961. In addition to radiation detector systems, they also manufacture nuclear reactor controls such as in-core flux monitoring systems, control rod logic systems, safety shutdown systems, and control room panels. These are supplied to all CANDU reactor sites worldwide as well as both DOE and commercial reactor customers in the United States. Scintrex has developed and 
now maintains a line of tritium monitors ranging from small, hand-held units to complex, multiroom, automated models.

The off-the-shelf models include the 209 and 309 models, which are both portable monitors. Their characteristics are listed in Table 7.

Table 7. Scintrex tritium monitors

Model No.

Flow rate, $\mathrm{L} / \mathrm{min}$

Detector air volume, $\mathrm{L}$

Detection limits, $\mu \mathrm{Ci} / \mathrm{m}^{3}$

Ranges, $\mu \mathrm{Ci} / \mathrm{m}^{3}$

Time constant

Accuracy

Gamma compensation

Zero drift

Noise $\underline{209}$

$0.5-1$

0.08

10

10-20,000

$<1 \mathrm{~min}$

$20 \mu \mathrm{Ci} / \mathrm{m}^{3} / \mathrm{mR} / \mathrm{h}$

Manual $\frac{309}{15}$

1.5

0.25

1

0-200,000 (autoranging)

$<1 \mathrm{~min}$ for $90 \%$ of reading $\pm 30 \%$ of reading $\left(<20 \mu \mathrm{Ci} / \mathrm{m}^{3}\right)$ $\pm 25 \%$ of reading $\left(>20 \mu \mathrm{Ci} / \mathrm{m}^{3}\right)$ $<3 \mu \mathrm{Ci} / \mathrm{m}^{3} / \mathrm{mR} / \mathrm{h}$ at dose rates $<100 \mathrm{mR} / \mathrm{h}$

Automatic compensation $0.3 \mu \mathrm{Ci} / \mathrm{m}^{3}{ }^{\circ} \mathrm{C}$

Neither existing monitor is capable of meeting the specification, primarily because of the sensitivity specification. ORNL has some experience with the Model 209 and found it to be very good in the tritium monitoring of areas around items such as tritium shipping containers, where high portability is desirable but low sensitivity is not required. The Emergency Preparedness Department of K-25 Operations has recently purchased two Model 309s but as yet has no operating experience with them. Other sites have also reported experience with these monitors, as given in Ref. 27.

\subsubsection{Response to Proposal Request}

Scintrex would initiate a development program of about 2-1/2 years' duration to develop a monitor that would meet the specifications. They indicated that the sensitivity requirement is an order of magnitude increase over that of present tritium monitors, and a development program is required to meet both it and the other specifications. The concentric ion chamber technology would be used, with careful attention to mechanical and electrical component design. A size increase over present tritium monitors is expected. Development work in electrometer sensitivity would also be undertaken. 
Scintrex proposes that the development program consist of a feasibility study to verify that the $0.1-\mu \mathrm{Ci} / \mathrm{m}^{3}$ detection limit is possible under the conditions specified and then a full monitor development program that would produce a monitor that would meet all of the specifications. These tasks are based on the company's present ionization detector technology, but they could also be a vendor for development of a scintillatorbased detector system if such a system were determined to be worthy of development.

The cost of the development program could be borne by a development contract or absorbed into the cost of the detector system. In the latter case, a market for the end product would have to be demonstrated.

\subsection{TECHNICAL ASSOCIATES}

Technical Assosciates (T/A) manufactures three types of ion chamber monitors and one proportional counter model. The proportional counter (SSS-33G1) is designed for counting the effluent from a gas chromatograph and is a laboratory instrument for measuring the tritium content of organic compounds in isotopic tracer work. The tritium labeled compounds are sorted according to species with the gas chromatograph, and then the tritium counter is used to detect the tritium content of the different species. As with other proportional counters, it requires addition of a counting gas such as methane or P-10.

The three ionization chamber systems (STG-4S, STG-5ATL, and STG-10ATL) are all compensated for gamma background with a duplicate background ion chamber. The tritium chambers have a volume of $50 \mathrm{~L}$, and this accounts for the additional sensitivity. One model (STG-5ATL) allows the tritium-containing air stream to be passed through the ionization chamber to detect total gas activity. Then the gas is passed through a separator (probably a Nafion membrane) to separate the HTO, which is passed to a second ion chamber. This allows the detection of tritium in the presence of other gases. Another model (STG-10ATL) collects the moisture in the sample on a cold finger in the form of ice as a sample concentration step. The regenerated sample is then passed through the ion chamber to monitor the tritium content. This monitor is inherently slower responding than the other two but is inherently more sensitive.

The specifications of the above three monitors are listed in Table 8.

These monitors appear to be applicable for this application. The off-the-shelf monitors probably cannot meet the ML-spec standard. The physical size of the system is a concern. This monitor suffers the same limitations of any other ion chamber system, namely, that its claimed sensitivity $\left(0.01 \mu \mathrm{Ci} / \mathrm{m}^{3}\right)$ has not been achieved in the field. ORNL does not have any experience with this company's monitor, and since the ion chamber is so large, it is possible that this monitor system can come closer to meeting the required sensitivity. 
Model No.

Flow rate

Detector air volume, $\mathrm{L}$

Detection limits, $\mu \mathrm{Ci} / \mathrm{m}^{3}$

Ranges, $\mu \mathrm{Ci} / \mathrm{m}^{3}$

Background

Calibration $\underline{\text { STG-4S }}$ STG-5ATL $\quad \underline{\text { STG-10ATL }}$

$\begin{array}{lll}50 & 50 & 50\end{array}$

$\begin{array}{lll}0.1 & 0.1 & 0.01\end{array}$

$0.1-10,000 \quad 0.1-10,000 \quad 0.1-$

10,000

Eliminated by subtracting balanced chambers. Smoke, dust, ion elimination filter, and deionizer reduce to negligible level.

Checked internally with tritium gas, gamma source.

Can be checked at one point with external beta source.

\subsubsection{Response to Proposal Request}

T/A specializes in tritium detection and currently offers several types of tritium air monitors. Shown below are their responses to the points in the preliminary specification. In this initial period the specifications are evolving, and they would not give cost estimates until the specifications have solidified to a greater extent. More information as to how these monitors will be used will also be required.

Existing T/A instruments meet the specifications for Sensitivity, Accuracy, Operating Range, Operating Background, Response Time, Alarm, and Self-Check Feature. In addition, existing personnel will be able to operate and maintain the instruments, an imbedded computer is available, and T/A monitors do have easily replaceable modules.

Other responses to specifications are listed below.

Calibration: There is no technical obstacle to building an instrument that will retain its $\pm 20 \%$ accuracy for 2 years. However, if this is to be maintained without any human adjustment or touch-up, then there will be the expense of providing a self-testing and self-adjusting automatic system.

Ruggedness: There is no technical obstacle to building tritium air monitors to meet these two MIL specs. However, there is considerable expense in design and in testing. We feel that these specifications should be invoked only if they are truly necessary. 
Size: $\quad$ Since T/A instruments already meet the sensitivity specification, we will not need larger chambers than we currently use.

Universal Contamination monitoring in gases is a standard T/A feature. Detection of Detection: tritium in dust is somewhat problematical because of the very short range of the tritium beta and because of artifacts introduced if dust enters the ion chamber or proportional counter. More information is required about the quantity of dust and the amount of tritium activity expected. It may be possible to combine an impactor system inside the ion chamber, but it will be necessary to change the impactor plate frequently.

EMI Noise T/A monitors have good noise rejection. A knowledge of how much EMI Immunity: that is expected is required.

Reliability: Ten-thousand-hour mean time between failures is quite achievable. The half-hour and 1-h times to repair are achievable for some repairs, but major repair and recalibration are a lengthy process because of low chamber current and long time constants necessitated by the very low levels of tritium that we are detecting.

Availability: $99.8 \%$ is achievable if time spent on scheduled maintenance and on periodic recalibration is not counted.

\section{COST, SCHEDULE, AND PERFORMANCE TRADE-OFFS}

This section describes a list of alternatives for technologies that would meet the operational requirements of the tritium monitor, together with the cost, schedule, and performance trade-offs necessary to develop a set of workable functional requirements.

\subsection{ALTERNATIVES LIST}

The following monitor types could be developed to meet the operational requirements. The potential solution is given in discussion with each detector system.

Ionization An ionization-chamber-based system would consist of a set of two ionizaChambers tion chambers, one of which is a flow cell for gas. The other is a sealed gamma compensation chamber. The inside surface of the flow cell chamber would be highly polished, and the chamber would be heated to reduce memory effects. The detector system would incorporate the best available technology of all commercial ion chamber manufacturers. 
Proportional The need for a counting gas would eliminate this type of system from Detectors consideration since a gaseous waste disposal system is not available.

Passive A passive-sampler-based system would consist of a set of passive samplers Samplers located throughout the ship in locations where ventilation air can contact them. Periodically, the sampler would be replaced, the scintillation cocktail (premixed) added, and the sampler counted in an on-board liquid scintillation counting system along with the appropriate blanks and calibration standards with a predetermined procedure.

Plastic A plastic scintillator detector system would consist of a thin fiber detector Scintillator in which the fibers are coupled to a light pipe that is, in turn, coupled to a Detectors set of two photomultiplier tubes. The sampled air flows through the detector.

Avalanche This detector has not been demonstrated at sufficient sensitivity to warrant Photodiode its consideration without considerable R\&D activities.

Detector

Electret An EIC- based system would consist of a series of EICs placed in strategic Ion Chamber locations around the ship. With each tritium chamber, a sealed EIC would be required for gamma compensation. The chambers would be handled in the same manner as the passive samplers above, except they would be counted electronically, in much the same way as direct reading dosimeters.

The following discussion considers issues relative to the overall tritium monitoring concept.

\subsubsection{Present Practice}

Present Navy practice ${ }^{28}$ for tritium monitoring involves several different aspects. To sample a storage bunker or other space, a tube is inserted into these spaces and an air sample withdrawn. On ships the missile space is similarly sampled but not the personnel space. This is because any leakage problem would be detected there first and since the two spaces are separated, give adequate warning of impending leakage. The personnel space air-conditioning condensate is counted for tritium, but urinalysis of personnel is not done routinely since a problem was never detected during periods when urinalysis was practiced. None of the spaces where weapons are located are "dead air spaces," and all have ventilation; however, on ships this is sometimes processed and returned in a closed loop. The normal background in the missile tubes is between 3 and $10 \mu \mathrm{Ci} / \mathrm{m}^{3}$, and they maintain an alarm level of $100 \mu \mathrm{Ci} / \mathrm{m}^{3}$. The reason for this high level is to reduce the incidence of false alarms, which tend to create a grave concern because of the enclosed space and the difficulty in venting it. There are two different types of monitors, one a 
Nuclear Research Corporation portable monitor, and the other a "militarized" version of a commercially available Overhoff Technologies monitor.

\subsubsection{State of Development}

Tritium monitors based on techniques other than ionization chambers or proportional counters probably cannot meet the operational requirements of the subject tritium monitoring system in a short length of time. Although the plastic scintillator detectors show promise and could possibly be made sensitive enough to detect tritium at the required levels, ionization chambers are developed to the point of having several different vendors available. It could be that modifying these detectors so that the operational requirements can be met is easier from a technical standpoint and more costeffective than conducting a development program for a monitor based on other techniques. However, a certain amount of compromise on some of the operational requirements will be necessary.

On the other hand, plastic scintillator detectors offer an advantage in ruggedness over ionization chambers as well as advantages in electronic stability and the ability to better discriminate against nontritium radiation sources. Given the state of development of plastic scintillators, all that would be required is the demonstration of a proof-ofprinciple followed by the development and testing of a prototype.

\subsubsection{Low-Level Tritium Dosimetry}

It is desired to have a single monitor that has a range capable of monitoring very low levels up to intermediate levels of tritium. The system should monitor tritium at a working concentration of $3-10 \mu \mathrm{Ci} / \mathrm{m}^{3}$, at a retained sensitivity of $0.1 \mu \mathrm{Ci} / \mathrm{m}^{3}$, while having the capability to monitor excursions of up to $10,000 \mu \mathrm{Ci} / \mathrm{m}^{3}$, all at an accuracy of $\pm 0.02 \mu \mathrm{Ci} / \mathrm{m}^{3}$, while never giving a false alarm. No existing monitor is capable of meeting all of these requested operational requirements, but several of the commercial monitors could meet slightly less restrictive standards.

It could be more effective to have two monitoring methods: one for the extremely low levels and one for some higher level. Tritium detection with ionization chambers is subject to the limitations discussed above. The most serious of these are memory effects, noise due to fluctuating gamma fields, and tritium diffusion into the compensating chamber. These effects are pronounced at low detection levels, and they all work toward reducing the sensitivity of the monitor over time. Monitoring tritium with an ionization chamber detector sensitive to $0.1 \mu \mathrm{Ci} / \mathrm{m}^{3}$ at a 3 - to $10-\mu \mathrm{Ci} / \mathrm{m}^{3}$ actual level will render the detector insensitive to the low levels of tritium detection in a relatively short period of time. Monitoring tritium with two detection methods could improve this situation by giving a monitor that can measure the extremely low levels together with a monitor that, while insensitive to extremely low levels, can reliably measure tritium at low levels.

Tritium detection by passive samplers in addition to a real-time ionization chamber monitor would be compatible with this idea. The passive samplers are relatively insensitive to rapid changes in tritium concentration and because they are discarded when 
changed, do not lose sensitivity to low tritium levels. Passive samplers are also usable by semiskilled personnel. The passive samplers could be located in a heating, ventilating, and air-conditioning (HVAC) system location(s) where they could monitor the ship for low-level concentrations of tritium. The passive samplers could be changed out weekly and counted using an on-board liquid scintillation counter, possibly built into the realtime monitor cabinet and operated with the same computer. In the event of ion chamber detector alarm, the passive samplers would be pulled and analyzed to confirm or negate the alarm event. The ionization chamber monitor would then not require low tritium level sensitivity, thus avoiding the attendant problems.

\subsubsection{Scintillation Detectors}

Because of the ability to electronically discriminate background gamma, scintillation-based detectors should be inherently lower in noise, and there is no compensation detector for tritium to diffuse into. However, memory effects in a scintillation detector are an unknown. The protium in the plastic fibers is subject to tritium exchange, which would tend to reduce sensitivity over a period of time. This could be as big a problem as it is with ionization chambers since contamination in this manner would be difficult to remove (the fiber bundle could be inexpensive to replace, however). Therefore, a scintillation-based tritium monitor may suffer the same performance degradation over time as an ionization-chamber-based system. However, because there are no data concerning this type of system, the degree is an unknown.

\subsection{SPECIFICATION ISSUES}

Several individual specifications in the operational requirements document are difficult to meet. The principal ones are listed below with a discussion of each.

\subsubsection{Neutron Background}

It is unclear why there is a requirement for such a high neutron background. A $0.1-\mathrm{rem} / \mathrm{h}$ neutron background is high from a personnel exposure standpoint and is a greater biological hazard than either the gamma or airborne tritium background. The effect of neutron irradiation on an ionization chamber is an unknown but is not expected to be significant.

\subsubsection{Sensitivity, Accuracy, Detector Size, and Response Time}

These specifications are written around an ionization-chamber-based system, and since a change in one specification affects the others, they are all tied together. The desired range of sensitivity is achievable in present monitors, but a penalty will be paid in response time or in ionization chamber size. Since it would appear that the size and weight restrictions are governing, increasing the ionization chamber size is not an option. This being the case, the only option is increasing the response time. This is not an 
attractive option if a single monitoring system is required, since fast response to a large leak is also a requirement. The best that can be hoped for is a compromise between sensitivity and response time.

Accuracy should be better defined and probably could be relaxed. An accuracy of $0.1 \mu \mathrm{Ci} / \mathrm{m}^{3} \pm 0.02 \mu \mathrm{Ci} / \mathrm{m}^{3}$ is not attainable with present technologies. However, it is possible that this level of accuracy is not required in a field instrument. If an alarm level of $2 \mu \mathrm{Ci} / \mathrm{m}^{3}$ is desired, then an error of $2 \sigma\left(\approx \pm 0.5 \mu \mathrm{Ci} / \mathrm{m}^{3}\right)$ is not unreasonable. This is because the incremental hazard of a tritium concentration of $2.5 \mu \mathrm{Ci} / \mathrm{m}^{3}$ is not significantly greater than the hazard from $2 \mu \mathrm{Ci} / \mathrm{m}^{3}$.

\subsection{SURVIVABILITY/VULNERABILITY}

No commercial tritium monitoring system is capable of meeting MIL-STD-2036 or MLL-S-901 in its present form. The production of a monitor that would meet these standards was one of the main unknowns with all of the vendors. The tests described in the required standards should be carefully reviewed as to their applicability.

\subsubsection{Universal Detection}

Detection of tritiated particulates is not possible with an ionization chamber. Ionization chambers do not function well unless the sampled air is filtered to remove particulates. Detection of particulates in general is accomplished through the use of a filter that traps the particulates in a sampled stream and a detector that counts the radioactivity in the particulate. Because the tritium beta has a short range, this technique is not possible for tritiated particulates. Generally, though, if there were tritiated particulates in the air, there should also be an equilibrium tritium gas concentration in the same air which should be detectable. Tritiated particulates cannot exist apart from tritiated gases, and vice versa. Since this is the case, a requirement to detect tritiated particulates appears to be unnecessary.

\subsubsection{Universal Monitor}

A single monitor cannot detect everything. Requiring a very low detection limit in a monitor that is subject to being exposed to high tritium levels will cause the monitor to cease being a low-level monitor if it is ever exposed to high tritium levels. For example, monitoring $3-10 \mu \mathrm{Ci} / \mathrm{m}^{3}$ with a monitor that is sensitive to $0.1 \mu \mathrm{Ci} / \mathrm{m}^{3}$ will make the monitor insensitive to $0.1 \mu \mathrm{Ci} / \mathrm{m}^{3}$ over a period of time. The tritium exposed components would require replacement. On the other hand, this would not be a problem for a monitor that never was exposed to high tritium levels. 


\subsubsection{Other Radioactive Species}

No specification is listed for other radioactive species such as radon. This may not be a problem for shipboard applications, but in some shore applications, radon rejection would improve sensitivity. Likewise, a monitor that is designed for no radon on ships could not be expected to perform as well in those applications where radon could be encountered.

\section{RISK ASSESSMENT}

The alternative solutions listed above are given in Table 9, with a discussion of the performance and schedule risk for each detector system given below. Performance risk is defined as the probability of not meeting the performance requirements listed in Tables 1 and 2. Cycle time is the estimated amount of time required to develop a successful prototype monitor. Schedule risk is defined as the probability of not meeting the desired development/procurement cycle.

Table 9. Performance and schedule risk assessment

Detector system type $\quad$ Performance risk $\begin{gathered}\text { Cycle time } \\ \text { (years) }\end{gathered} \quad$ Schedule risk

$\begin{array}{llll}\text { Ionization chambers } & \text { Low } & 1 & \text { Low } \\ \text { Passive samplers } & \text { Low } & 1 & \text { Low } \\ \text { Plastic scintillators } & \text { Low } & 2 & \text { Low } \\ \text { Avalanche photodiodes } & \text { High } & 3-5 & \text { High } \\ \text { Electret ion chambers } & \text { Medium } & 3 & \text { Low }\end{array}$

Ionization chamber technology could be expected to produce a workable monitor in the shortest time period. The state of development with several competing vendors makes this technology the best presently available. All of the vendors contacted indicated that they could now produce a monitor that could meet the operational requirements; therefore, a competitive procurement is possible. However, since vendors generally tend to overstate their capabilities, it appears that all the vendors have lower requirements in 
sight than the specification requires, thinking that some of these standards would be lowered.

Passive samplers are used in several locations, ${ }^{6,7}$ and the only real issue is one of developing an appropriate system for the application. Also, the operation of a liquid scintillation system would be required to be initiated, but this is in concert with current plans for contamination monitoring. ${ }^{28}$ It is thought that these types of detectors could function best as low-level tritium detectors, as well as backup detectors for other detection methods.

Some R\&D would be required for a plastic scintillator detector system, starting with proof-of-principle experiments. A prototype detector system could be developed shortly thereafter if it were designed around modifying a commercially available system. This has been done at Savannah River for the liquid effluent monitor previously described, and a similar program could be conducted to develop an air monitor. Then a vendor (probably the supplier of the system that was modified) would be required to produce the actual monitor. The performance and schedule risk are judged to be the same as for ionization chamber technology, but it would require more time for development of the scintillation monitor.

Fundamental detector improvement would be required for avalanche photodiode detectors, which could incur a significant investment. A monitor based on this technique is probably several years away.

Some R\&D would be required for EIC detectors, in the area of making the detector more sensitive and in proof-of-principle. A monitor based on this technique is probably also several years away.

\section{CONCLUSIONS AND RECOMMENDATIONS}

It is not believed that the Navy wishes to participate in a detector development program as the principal funding source if there are existing monitors that could meet the requirements without significant development. Present ionization chambers cannot meet the desired requirements: a working concentration of $3-10 \mu \mathrm{Ci} / \mathrm{m}^{3}$, a retained sensitivity of $0.1 \mu \mathrm{Ci} / \mathrm{m}^{3}$, the capability to monitor excursions of up to $10,000 \mu \mathrm{Ci} / \mathrm{m}^{3}$, an accuracy of $\pm 0.02 \mu \mathrm{Ci} / \mathrm{m}^{3}$, and never giving a false alarm. Some compromise either of requirements or of detection methods will be necessary. If other detector systems such as a plastic scintillator are ever developed to the point where they are commercially available, then these systems should be evaluated against ionization chamber technology at that time.

It is concluded that the present requirements of Navy personnel are best met with ionization chamber technology. The desired detector performance specifications are not within the range of existing ionization chamber technology but will require some compromise with the desired performance specifications in order to produce a workable detector system. The use of passive samplers is recommended for the very low level of 
tritium monitoring where they are practical. It is suggested that personnel spaces be monitored with passive samplers and that weapons spaces also be monitored, in addition to using ionization chamber monitors, as a confirmatory method. Although the present practice of monitoring air-conditioning condensate is the same type of measurement, the passive sampler technique offers more control over the monitoring.

An outline specification that encompasses the state of the art of ionization chamber technology is given in Table 10. A detector system using this information is thought to be obtainable from most of the vendors contacted.

Table 10. Recommended outline specification for ion-chamber-based tritium monitor

Item performance Specification

Sensitivity

Provide continuous monitoring of tritium in gases. Detect $1 \mu \mathrm{Ci}$ tritium $/ \mathrm{m}^{3}$ of gas in a $0.1-\mathrm{mR} / \mathrm{h}{ }^{60} \mathrm{Co}$ background and a $0.1-\mathrm{mrem} / \mathrm{h}$ multienergy neutron background after exposure to a continuous atmosphere of $10 \mu \mathrm{Ci} / \mathrm{m}^{3}$ elemental tritium $/ \mathrm{m}^{3}$.

Accuracy Measure tritium at the above sensitivity with a $\pm 2 \sigma$ accuracy at the $95 \%$ confidence level.

Operating range $\quad 1$ to $10,000 \mu \mathrm{Ci}$ tritium $/ \mathrm{m}^{3}$ of gas.

Operating

background

Operate without false alarm with the alarm set at $20 \mu \mathrm{Ci} / \mathrm{m}^{3}$ in a greater than $1-\mathrm{mR} / \mathrm{h}{ }^{60} \mathrm{Co}$ background and a $0.1-\mathrm{mrem} / \mathrm{h}$ multienergy neutron background.

Calibration Hold calibration at any point on the operating range with an accuracy of $\pm 10 \%$ for 2 years.

Response time $\quad 63 \%$ response to step input of $20 \mu \mathrm{Ci} / \mathrm{m}^{3}$ within $2 \mathrm{~min}$.

Physical dimensions $18 \times 18 \times 18$ in. maximum.

Ionization chamber Two-liter, heated, constructed of highly polished and passivated materials, can be separated from electronics.

Alarm Audible and visual, capable of being set anywhere on the operating range. 
Item performance

Specification

Other Features

Instrument check Self-check feature built-in.

Computer Embedded computer for operator/maintenance prompting with external computer hardware interface.

Construction Ionization chambers, preamplifier, electrometer, and pumping system should be of easily replaceable modular construction.

Reliability/Availability/Maintainability

Ruggedness MIL-S-901 Class I grade A shock test and MIL-STD-2036 type I vibration test should be better defined.

Reliability Electronics reliability should be in the range of $10,000-\mathrm{h}$ mean time between failures, $1 / 2$ - $\mathrm{h}$ mean time to repair (at use site), 1-h for intermediate-level problem.

Availability Overall availability should be $99.8 \%$, excluding pumping system and time required for calibration.

Maintainability Capable of being operated and maintained by existing personnel with minimal training. 


\section{REFERENCES}

1. M. J. Wood, R. G. C. McElroy, R. A. Surette, and R. M. Brown, "Tritium Sampling and Measurement," Health Phys. 65 (6), 610-627 (December 1993).

2. Gheorge Vâsaru, Tritium Isotope Separation, CRC Press, 1993, Chap. 4.

3. IAEA Technical Report Series No. 324, Safe Handling of Tritium, Review of Data and Experience, International Atomic Energy Agency, Vienna, 1991.

4. R. A. Jalbert, A Tritium Monitor for Fusion Reactors, LA-9382-MS, August 1982.

5. A. E. Bainbridge, "Determination of Natural Tritium," Rev. Sci. Instrum. 36(12), 1779 (1965).

6. R. L. Otlet, A. J. Walker, and C. J. Caldwell-Nichols, "Practical Environmental, Working Area and Stack Discharge Samplers, Passive and Dynamic, for Measurement of Tritium as HTO and HT," Fusion Technol. 21, 550-555 (March 1992).

7. M. J. Wood and W. J. G. Workman, "Environmental Monitoring of Tritium in Air with Passive Diffusion Samplers," Fusion Technol. 21, 529-535 (March 1992).

8. R. A. Allen, D. B. Smith, R. L. Otlet, and D. S. Rawson, "Low Level Tritium Measurements in Water," Nucl. Instrum. Methods 45, 61 (1966).

9. P. I. Gant and K. Yang, "Separation of Hydrogen Isotopes by Gas-Solid Chromatography," Science 129, 1548 (1959).

10. H. Perschke, "Tritium Enrichment by Gas Chromatography," Nature (London) 209(5027), 1021 (1966).

11. C. Menninga, and R. L. Brodzinski, A Design Manual for a Well-Logging Probe Capable of Measuring Tritium, PNL-4069, October 1981.

12. C. Menninga, and R. L. Brodzinski, Well-Logging Probe for Measuring Tritium: Construction and Operating Manual, PNL-4620, April 1983.

13. F. Sannes and B. Banville, A Portable Tritium Monitor, AECL-2283, July 1965.

14. R. V. Osborne, "Detector for Tritium in Water," Nucl. Instrum. Methods 77, 170-172 (1970). 
15. A. N. Singh, M. Rathnakaran, and K. G. Vohra, "An On-Line Tritium in Water Monitor," Nucl. Instrum. Methods A236, 159-164 (1985).

16. A. N. Singh and M. Rathnakaran, "An Instrument for On-Line Monitoring of Tritium-in-Air in Heavy Water Reactors," Nucl. Instrum. Methods A258, 250-254 (1987).

17. A. N. Singh, M. V. Ramana Murthy, and M. G. Kadwani, "A Detector for Continuous Monitoring of Low Levels of Tritiated Water in Presence of High Gamma Background," Nucl. Instrum. Methods 153, 397-400 (1978).

18. R. V. Osborne, Development of a Monitor for Tritiated Water Vapour in the Presence of Noble Gases, AECL-4303, September 1972.

19. K. J. Hofstetter, Development of Aqueous Tritium Effluent Monitor, WSRC-RP89-397, October 1989.

20. K. J. Hofstetter and H. T. Wilson, "Aqueous Effluent Tritium Monitor Development," Fusion Technol. 21, 446-451 (March 1992).

21. K. J. Hofstetter and H. T. Wilson, Continuous Effluent Water Monitor at the Savannah River Site, WSRC-MS-92-163, September 1993.

22. Close-Out Document for the Solenoidal Detector Collaboration (SDC), SDT000399, Oct. 31, 1994.

23. W. J. McGann, G. Entine, R. F. Farrell, A. Clapp, and M. R. Squillante, "Radiation Monitoring Devices, Inc., Solid State Detector for Monitoring Low Levels of Tritium," Fusion Technol. 14 (September 1988).

24. R. A. Surette, "A Novel Tritium Process Monitor That Uses an X-Ray Detector," Nucl. Instrum. Methods A 337, 588-593 (1994).

25. P. Kotrappa, J. C. Dempsey, and L. R. Stieff, "Recent Advances in Electret Ion Chamber Technology for Radiation Measurements," Radiat. Prot. Dosim. 47, (1/4), 461-464 (1993).

26. N. Sion, "Ontario Hydro, Tritium Detection and Measurement at Darlington's Tritium Removal Facility (TRF)," Fusion Technol. 14, 1071-1078 (September 1988).

27. C. M. Shultz, S. R. Bokwa, R. E. Johnson, and J. M. Miller, "Tritium Monitoring and Analysis in the CRNL Tritium Laboratory," Fusion Technol. 14, 1061-1065 (September 1988). 
28. Personal communication, Lt. Cdr. Grosso and George Garrett, USN, July 10, 1995. 


\section{BIBLIOGRAPHY}

Anderson, D. F., and Hiebert, R. D., "A Wide Range Tritium Monitor," IEEE Trans. Nucl Sci., NS-29 (1), 819-821 (February 1982).

Carfagno, D. G., Farmer, B. M., and Lacy, V. C., "Comparison of Liquid Scintillation Cocktails Used for Tritium Analyses at Mound Facility," Proceedings, Tritium Technology in Fission, Fusion and Isotopic Applications, Dayton, Ohio, April 29-May 1, 1980, American Nuclear Society Topical Meeting, CONF-800427, 1980.

Chiles, M. M., Evaluation of Thin $\mathrm{CaF}_{2}(\mathrm{Eu})$ Scintillator for Detecting Tritium, ORNL/TM-10115, Oak Ridge Natl. Lab., October 1986.

Dominik, W., et al., "A Gaseous Detector for High-Accuracy Autoradiography of Radioactive Compounds with Optical Readout of Avalanche Positions," Nucl. Instrum. Methods A268, 779-787 (1989).

Dunn, D. L., "Effluent Treatment Facility Tritium Emissions Monitoring," Fusion Technol. 21, 442-445 (March 1992).

Gentile, C. A., "Tritium Detectors Employed at the Tokamak Fusion Test Reactor," Fusion Technol. 14 (September 1988).

Harrison, K. G., Waldron, J. C., and Gibson, J. A. B., "An Evaluation of the CRNL/CFFTP HT/HTO Discriminating Monitor," Fusion Technol. 14, 1054-1057 (September 1988).

Hoots, S. S., and Barry, P. E., "HT/HTO MPC Detector Response Under Field Conditions," Proceedings, Tritium Technology in Fission, Fusion and Isotopic Applications, Dayton, Ohio, April 29-May 1, 1980, American Nuclear Society Topical Meeting, CONF-800427, 1980.

Jalbert, R. A., A Tritium-Gas/Water-Vapor Monitor: Tests and Evaluation, LA9383-MS, July 1982.

Jalbert, R. A., Monitoring Tritium in Air Containing Other Radioactive Gases, LA-9514-MS, September 1982.

Jalbert, R. A., "A New Tritium Monitor for the Tokamak Fusion Test Reactor," Fusion Technol. 8 (September 1985). 
Makepeace, J. L., et al., "Intercomparison of Internal Proportional Gas Counting of ${ }^{85} \mathrm{Kr}$ and ${ }^{3} \mathrm{H}, "$ Nucl. Instrum. Methods A339, 343-348 (1994).

McElroy, R. G. C., and Osborne, R. V., "Developments in Tritium Monitoring," Proceedings, Tritium Technology in Fission, Fusion and Isotopic Applications, Dayton, Ohio, April 29-May 1, 1980, American Nuclear Society Topical Meeting, CONF-800427, 1980.

McElroy, R. G. C., Osborne, R. V., and Surette, R. A., "A Monitor for Separate Determination of HT and HTO," IEEE Trans. Nucl. Sci. NS-29 (1), 816818 (February 1982).

McElroy, R. G. C., Tritium Monitoring, CRNL-2739-1 (Rev. 1), April 1987.

McElroy, R. G. C., and Johnson, J. R., "A Review of the Need for Species Specific Tritium Monitors," Fusion Technol. 14, 1021-1025 (September 1988).

Moghissi, A. A., Kelley, H. L., Phillips, C. R., and Regnier, J. E., "A Tritium Monitor Based on Scintillation," Nucl. Instrum. Methods 68, 159 (1969).

Muramatsu, M., Koyano, A., and Tokunaga, N., "A Scintillation Probe for Continuous Monitoring of Tritiated Water," Nucl. Instrum. Methods, 54, 325-326 (1967).

Murphy, L. P., Duce, F. A., and Fernandez, S. J., Continuous Tritium, Carbon-14, Iodine-129, and Krypton-85 Monitor for Nuclear Facility Offgas, ENICO1092, October 1981.

Östlund, Göte, and Lundgren, L., Stockholm Natural Tritium Measurements, I, Tellus XVI, 1 (1964).

Petek, M., Ramey, D. W., Taylor, R. D., and Kobisk, E. H., "Tritium Isotope Separation from Light and Heavy Water by Bipolar Electrolysis," Proceedings, Tritium Technology in Fission, Fusion and Isotopic Applications, Dayton, Ohio, April 29-May 1, 1980, American Nuclear Society Topical Meeting, CONF-800427, 1980.

Quaiattini, R. J., Graham, W. R. C., Wood, M. J., and McElroy, R. A., "Performance of a Wetproofed Catalyst in an Ambient Temperature Discriminating Tritium Sampler," Fusion Technol. 14 (September 1988).

Specht, S., and Vogl, J., "Isotopic Separation Processes for Tritium Contaminated Water from a Reprocessing Plant," Kerntechnik 54(4), 263-269, (1989). 


\section{APPENDIX A:}

\section{COMPANIES WITH COMMERCIAL TRITIUM MONITORING EXPERIENCE}

Becton Dickinson Diagnostic Instrument Systems

7 Loveton Circle

Sparks, MD 21152

410-316-4000

800-638-8656

Fax: 410-584-2967

Contact: Agnes L. Windsor

EG\&G Berthold

100 Midland Road

Oak Ridge, TN 37831-0895

615-483-2202

800-251-9750

Fax: 615-483-0396

Contact: Benson Davis

femto-TECH, Inc.

P. O. Box 8257

325 Industry Drive

Carlisle, $\mathrm{OH} 45005$

\section{3-746-4427}

Fax: 513-746-9134

Contact: Rick Straub

Nuclear Measurements Corporation

2460 N. Arlington Ave.

Indianapolis, IN 46218

317-546-2415

Fax: $317-543-4420$ 
Nuclear Research Corporation

125 Titus Ave.

Warrington, PA 18976

215-343-5900

Fax: $215-343-4670$

Overhoff Technology Corporation

P. O. Box 182

1160 U.S. Route 50

Milford, $\mathrm{OH}$ 45150-9705

513-248-2400

Fax: 513-248-2402

Contact: Mario Overhoff

Scintrex, Limited

222 Snidercroft Road

Concord, Ontario, Canada LAK1B5

905-669-2280

Fax: 905-669-5132

Contact: Andrew Dearham

Dr. Larry McNelles

Technical Associates

7051 Eton Avenue

Canoga Park, CA 91303

818-883-7043

Fax: 818-883-8103

Contact: Bob Goldstein 


\section{APPENDIX B:}

\section{SPECIFICATION FOR TRITIUM MONITOR SENT FOR PROPOSAL REQUEST}

Item

Sensitivity

Accuracy

Operating Range

Operating

Background

Calibration

Response Time

Alarm

Ruggedness

\section{Specification}

Detect $0.1 \mu \mathrm{Ci}$ tritium $/ \mathrm{m}^{3}$ of gas in a $0.1-\mathrm{mR} / \mathrm{h}{ }^{60} \mathrm{Co}$ background and a $0.1-\mathrm{rem} / \mathrm{h}$ multienergy neutron background.

Measure tritium at the above sensitivity with a $\pm 20 \%$ accuracy at the $95 \%$ confidence level.

0.1 to $10,000 \mu \mathrm{Ci}$ tritium $/ \mathrm{m}^{3}$ of gas.

Operate without false alarm with the alarm set at $2 \mu \mathrm{Ci} / \mathrm{m}^{3}$ or greater in a $1-\mathrm{mR} / \mathrm{h}{ }^{60} \mathrm{Co}$ background and a $0.1-\mathrm{rem} / \mathrm{h}$ multienergy neutron background.

Hold calibration at any point on the operating range with an accuracy of $\pm 20 \%$ for 2 years.

Respond to step input of $0.2 \mu \mathrm{Ci} / \mathrm{m}^{3}$ within $2 \mathrm{~min}$.

Audible and visual, capable of being set anywhere on the operating range.

MIL-S-901 Class I grade A shock test and MIL-E-16400 type I vibration test, including temperature and humidity for range 4 requirements.

\section{Additional Specifications}

- Self-check feature built-in.

- The detector cannot be made larger than presently available detectors.

- Universal detection and continuous monitoring of tritium in both dusts and gases.

- The detector should be capable of providing EMI noise immunity and operation without false alarms. 
- Capable of being operated and maintained by existing personnel with minimal training.

- Embedded computer for operator/maintenance prompting.

- High priority should be given to use of easily replaceable modules.

- Reliability should be in the range of $10,000-\mathrm{h}$ mean time between failures, $1 / 2-\mathrm{h}$ mean time to repair (at use site), 1-h for intermediate-level problem.

- Overall availability should be $99.8 \%$. 


\section{APPENDIX C:}

\section{femto-TECH QUESTIONS AND SUGGESTIONS FOR TRITIUM MONITOR}

In their proposal response, femto-TECH had the following questions:

1. Is the unit to be a hand-held portable or a rack mount unit?

2. Will the detector be part of the control chassis or an external device?

3. What are the maximum physical dimensions of the unit? Its maximum weight?

4. What power source will be used, external or internal batteries? Are there restrictions on the type of batteries (such as lithium, metal hydride, or mercury)?

5. What power (voltage, current, frequency, etc.) is available?

6. Should the unit contain an internal or external pump, or should the detector work on passive diffusion?

7. If the unit is a sealed chamber with active pumping, most small, low-power pumps only have a 3000 - to 4000 -h pumping life for the diaphragm. Is pump failure considered in the reliability requirement of 10,000 -h mean time between failures?

8. Should the detector be limited to materials of construction that have minimum radioisotopic effect due to the tritium? Highly polished 304 stainless steel is usually the material of choice.

9. While a $0.1-\mu \mathrm{Ci} / \mathrm{m}^{3}$ level of sensitivity is achievable, the practical reality is that after an instrument is exposed to levels of several thousand microcuries (the specification calls for 10,000 ), the detector builds up a background that may not be easily reduced to the $0.1-\mu \mathrm{Ci}$ range again without replacement of most of the detector components. What methods of background reduction and/or offset are acceptable?

10. Should the alarm level be adjustable? After the unit has been contaminated, the alarm level may need to be changed.

11. What is the allowable time after power up to achieve stability (several minutes, typically)? 
12. What should be the operating environmental ranges (such as temperature and barometric pressure)?

13. Since the tritium concentration measurement is a function of temperature through the PVT gas law, should the instrument measure the sample temperature and automatically correct for temperature?

14. Should the display be visible in low-light conditions (define low light)? The $0.1-\mu \mathrm{Ci}$ sensitivity implies a digital display.

15. Should the electronic zero of the instrument be operator adjustable (or just calibration lab setable)? Should this adjustment use a locking shaft control or an electronic button?

16. Are any external outputs required such as a computer hardware interface (such as RS-232C)?

17. Should the unit save any data?

18. Should all production units be calibrated with a tritium gas standard or will calibrations be performed by the end user (typically, the end user)?

femto-Tech made these suggestions for the monitor design features based on their knowledge of the intended use.

1. The accuracy specification needs to detail any exceptions.

2. The electronics should not require drying tubes to maintain insensitivity to humidity.

3. The use of a counting gas (such as P10) or cocktail solutions should not be allowed.

4. The unit should allow calibration by the evacuation/backfill method, which limits the sources of calibration errors to the NIST-traceable standard gas and the pressure transducer. The calibrated volume method allows many more potential sources of errors as well as not necessarily duplicating the operational environment.

5. If the gamma background (from the ${ }^{60} \mathrm{Co}$ ) is nonvarying, offsetting the gamma is relatively simple. Active gamma compensation is more expensive. 



\section{INTERNAL DISTRIBUTION}

$\begin{aligned} \text { 1-5. } & \text { J. R. DeVore } \\ 6 . & \text { G. T. Alley } \\ \text { 7-12. } & \text { M. A. Buckner } \\ 13 . & \text { B. G. Eads } \\ \text { 14. } & \text { R. A. Hess } \\ \text { 15. } & \text { J. M. Jansen } \\ 16 . & \text { D. W. McDonald } \\ 17 . & \text { G. N. Miller } \\ 18 . & \text { M. A. Phipps }\end{aligned}$

1-5. J. R. DeVore

7-12. M. A. Buckner

13. B. G. Eads

14. R. A. Hess

15. J. M. Jansen

17. G. N. Miller

18. M. A. Phipps

\section{EXTERNAL DISTRIBUTION}

28. Daniel Cross-Cole, Commander, Naval Sea Systems Command, NAVSEA 04-R (Dan Cross-Cole), 2531 Jefferson Davis Highway, Arlington, VA 22242-5160

29. H. B. Becker, Commander, Naval Sea Systems Command, NAVSEA 04-R (H. B. Becker), 2531 Jefferson Davis Highway, Arlington, VA 22242-5160

30. Ron Moore, The RM Group, Inc., 12024 Broadwood Drive, Knoxville, TN 37922

31. David Norton, Houston Advanced Research Center, 4800 Research Forest Drive, The Woodlands, TX 77381

32. M. M. Sevik, Carderock Division, Naval Surface Warfare Center, Code 70 , Bethesda, MD 20084-5000

33. Ernesto Suarez, Pratt \& Whitney, P.O. Box 109600, Mail Stop 716-87, West Palm Beach, FL 33410-9600

34-35. Office of Scientific and Technical Information, U.S. Department of Energy, P.O. Box 62, Oak Ridge, TN 37831 